\title{
New insights into the phylogeny, systematics and DNA barcoding of Nemertea
}

\author{
Sebastian Kvist ${ }^{\mathrm{A}, \mathrm{C}}$, Christopher E. Laumer ${ }^{\mathrm{A}}$, Juan Junoy ${ }^{\mathrm{B}}$ and Gonzalo Giribet ${ }^{\mathrm{A}}$ \\ ${ }^{A}$ Museum of Comparative Zoology, Department of Organismic and Evolutionary Biology, Harvard University, \\ 26 Oxford Street, Cambridge, MA 02138, USA. \\ ${ }^{B}$ EU_US Marine Biodiversity Research Group, Dpto de Ciencias de la Vida and Instituto Franklin, Universidad de \\ Alcalá, E-28871 Alcalá de Henares, Spain. \\ ${ }^{\mathrm{C} C}$ Corresponding author. Email: skvist@fas.harvard.edu
}

\begin{abstract}
Although some clades of ribbon worms (phylum Nemertea) are consistently recovered with high support in molecular phylogenies, the placement and inter-relationships of some taxa have proven problematic. Herein, we performed molecular phylogenetic analyses aimed at resolving these recalcitrant splits, using six loci (nuclear 18S rRNA, 28S rRNA, histones $\mathrm{H} 3$ and $\mathrm{H} 4$, and mitochondrial $16 \mathrm{~S}$ rRNA and $\mathrm{COI}$ ) for 133 terminals, with particular emphasis on the problematic families Hubrechtidae and Plectonemertidae. Three different datasets were used for phylogenetic analyses and both maximum likelihood and maximum parsimony methodologies were applied. All but one of the resulting tree topologies agree on the paraphyly of the class Palaeonemertea, whereas Heteronemertea, Hoplonemertea, Polystilifera, Monostilifera and Hubrechtidae are always recovered as reciprocally monophyletic. Hubrechtidae is sister group to Heteronemertea (the Pilidiophora hypothesis) only when length variable regions of $18 \mathrm{~S}$ rRNA and 28S rRNA are excluded. Moreover, the terrestrial and freshwater family Plectonemertidae is recovered with high support and the implications of this finding are further discussed. Finally, we evaluate the utility of DNA barcoding for specimen identification within Nemertea using an extended dataset containing 394 COI sequences. Results suggest that DNA barcoding may work for Nemertea, insofar as a distinct barcoding gap (the gap between the maximum intraspecific variation and the minimum interspecific divergence) may exist, but its recognition is regularly hampered by low accuracy in species level identifications.
\end{abstract}

Additional keywords: cytochrome $c$ oxidase subunit I, Hubrechtidae, Plectonemertidae, Pilidiophora.

Received 6 December 2013, accepted 5 February 2014, published online 30 June 2014

\section{Introduction}

Even though no universal agreement exists on the number of recognised species of ribbon worms (phylum Nemertea), current estimates suggest that the phylum accommodates over 1200 named species (Gibson 1995; Kajihara et al. 2008; Sundberg and Gibson 2008; Zhang 2011; Appeltans et al. 2012), placing it in an intermediate range among invertebrate phyla. Representatives are predominantly known from marine benthic intertidal communities, although some lineages have adapted to marine pelagic environments as well as terrestrial or freshwater habitats (Moore and Gibson 1981, 1985, 1988). The majority of nemerteans are active carnivores (e.g. Caplins et al. 2012) and use an eversible proboscis, enclosed by a rhyncocoel, to capture prey - a structure that is unique to the phylum (Schultze 1851; Gibson 1985). Others are scavengers or commensals, and some symbiotic bdellonemerteans have transitioned to become specialised suspension-feeders (Gibson 1967; Bell and Hickman 1985; McDermott and Roe 1985). Nemerteans are unsegmented or pseudosegmented (e.g. species of the genus Annulonemertes; Berg 1985; Kajihara et al. 2000; Sundberg and Strand 2007) bilaterally symmetrical worms with almost unrivalled variation in body length, ranging from only a few millimetres to over $30 \mathrm{~m}$ (McIntosh 1873). Despite this variation, there is a notable paucity of morphological characters useful for diagnosing nemertean species, genera or even families (e.g. Rogers et al. 1995; Chen et al. 2010; Strand et al. 2013). However, at the class level the characteristic stylet found at the end of the proboscis is a clear synapomorphy for Enopla (including Hoplonemertea and Bdellonemertea); this structure is lacking from other clades formerly grouped together in the paraphyletic class Anopla (including Heteronemertea and Palaeonemertea). Separation of Enopla from other clades is further supported by the relative placement of the mouth and proboscis pore: in Heteronemertea and Palaeonemertea the mouth and the proboscis pore are separate, whereas the pore is fused with the mouth in most monostiliferan hoplonemerteans (Härlin and Sundberg 1995; Chernyshev 2003). Considering the simplicity of the nemertean body plan (see Figs 1 and 2 for some representative taxa), especially after fixation, and the high degree of homoplasy in the commonly used morphological 

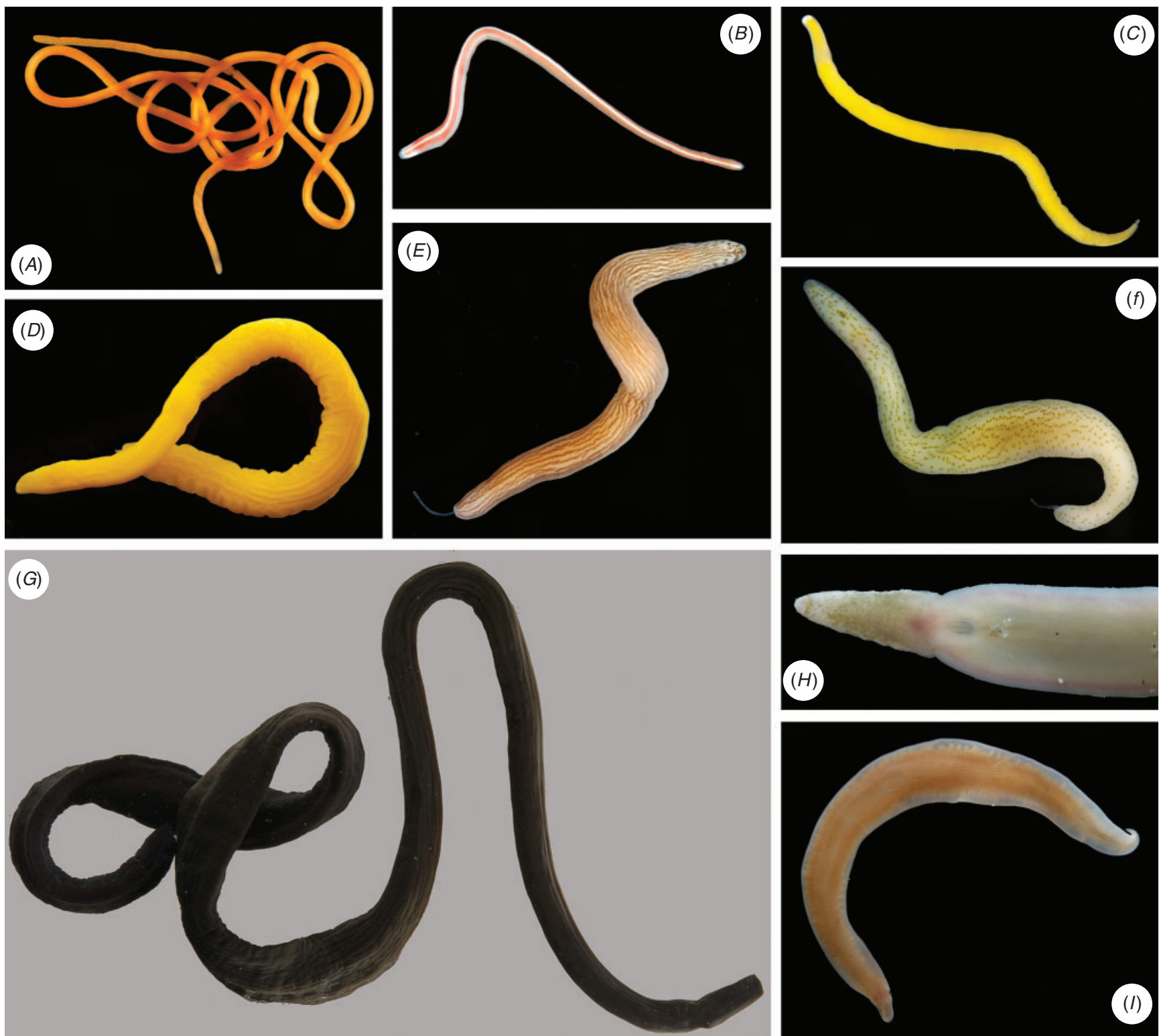

Fig. 1. Live habitus of selected specimens. Photos by G. Giribet, except where specified. (A) Cephalotrix bipunctata Bürger, 1892 IZ-133009 (Los Escullos, Cabo de Gata, Almería, Spain, 7.xii.2010; photo J. Junoy). (B) Micrura sp. IZ-132529 (Bocas del Toro, Panama, 21.iii.2013). (C) Micrura sp. IZ-132532 (Bocas del Toro, Panama, 22.iii.2013). (D) Micrura sp. IZ-133724 (Bocas del Toro, Panama, 17.iii.2010). (E) Micrura rubramaculosa (Bocas del Toro, Panama, 19.iii.2011), specimen conspecific with IZ-132531. (F) Micrura chlorapardalis IZ-132530 (Bocas del Toro, Panama, 20.iii.2013). (G) Notospermus sp. (Bocas del Toro, Panama, 15.iii.2010), conspecific with specimen IZ-132528. (H) 'Notospermus' sp. IZ-134234 (Stradbroke Island, Queensland, Australia, 16.x.2008). (I) Reptantia sp. IZ-133024 (Bocas del Toro, Panama, 12.iii.2012). Additional specimen details can be found in MCZbase (http://mczbase.mcz.harvard.edu/).

characters (Sundberg and Svensson 1994; Schwartz and Norenburg 2001), it is probable that the phylum harbours a significant proportion of overlooked species diversity (Appeltans et al. 2012). One way of circumventing the inadequacy of morphological characters in identifying and diagnosing specimens is to employ molecular tools, such as DNA taxonomy or DNA barcoding, to alleviate this situation (e.g. Mahon et al. 2010; Sundberg et al. 2010; Strand and Sundberg 2011). However, such an endeavour presupposes both an a priori knowledge of the disposition of interspecific and intraspecific genetic variation within the target group, and a well-sampled genetic database for comparative purposes; these elements are largely lacking for nemerteans (Kvist 2013).

While Nemertea is often recovered as the sister group to Brachiopoda in metazoan phylogenies (e.g. Dunn et al. 2008; Hejnol et al. 2009; but see also supplementary material in Kocot et al. 2011 as a contrary example), together forming the clade Kryptrochozoa (Giribet et al. 2009), some internal relationships of the phylum remain unsupported. At the ordinal level, Sundberg et al. (2001) recovered a polyphyletic 

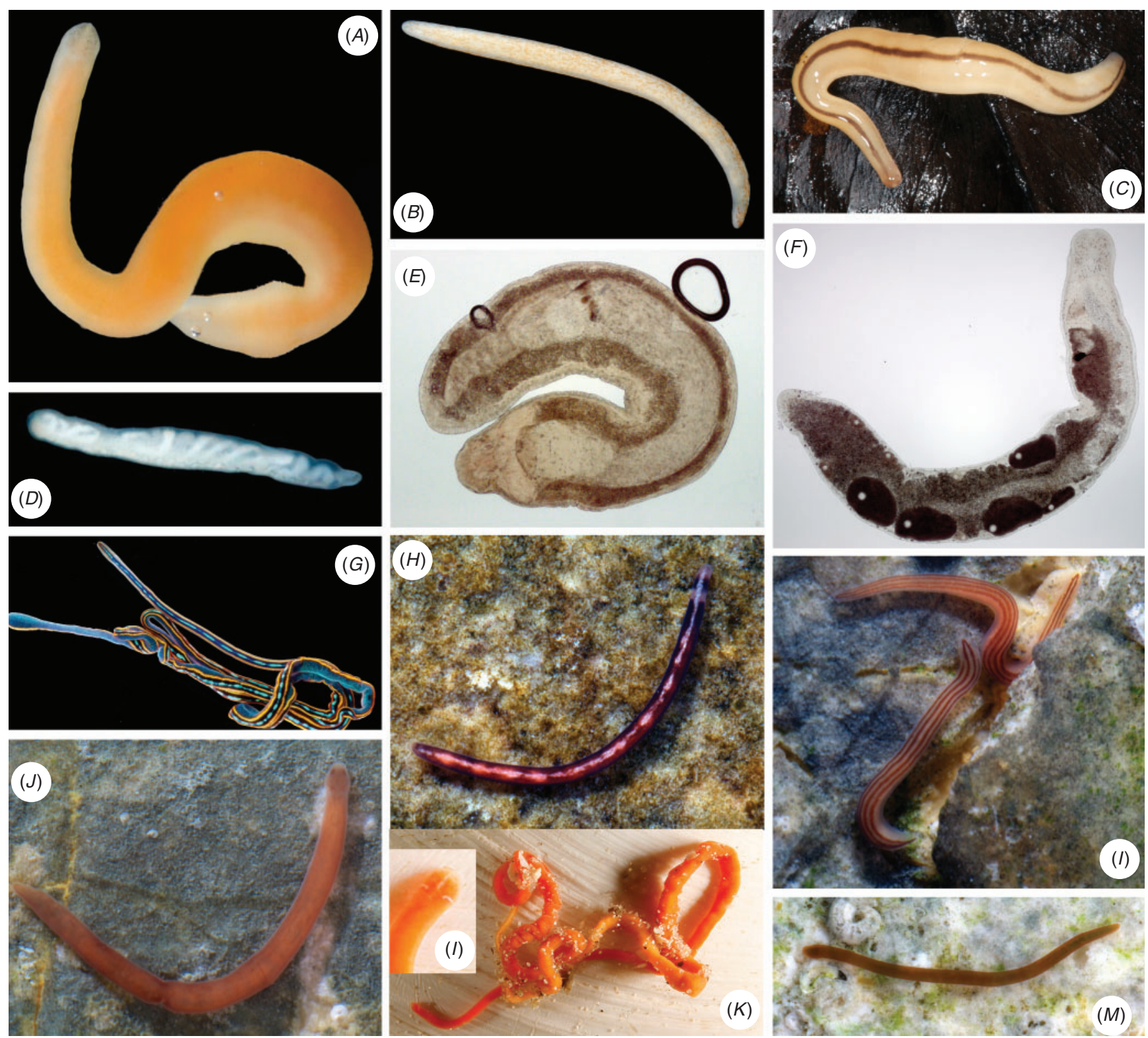

Fig. 2. Live habitus of selected specimens. Photos by G. Giribet, except where specified. (A) Amphiporidae sp. IZ-132476 (Isla Alborán, 22.ix.2011; photo J. Junoy). (B) Nemertea sp. IZ-132533 (Bocas del Toro, Panama, 22.iii.2013). (C) Geonemertes sp. IZ-132534 (Bocas del Toro, Panama, 20.iii.2013). (D) cf. Potamonemertes percivali IZ-25172 (Rangitata River, W of Ashburton, New Zealand; photo N. Boustead). (E) Plectonemertidae sp. A IZ-25174 (Kinglake Road, Melbourne, Australia; photo C. Laumer). (F) Plectonemertidae sp. B IZ-25175 (Yea River, Melbourne, Australia; photo C. Laumer). (G) Monostilifera sp. IZ133023 (Bocas del Toro, Panama, 12.iii.2012). (H) Oerstedia sp. IZ-132743 (Cabrera, Balearic Islands, Spain, 29.vii.2012). (I) Tetrastemma vittigera IZ-25171 (Cabrera, Balearic Islands, Spain, 28.vii.2012). (J) Tetrastemmatidae sp. IZ-132537 (Cabrera, Balearic Islands, Spain, 28.vii.2012). (K, L) Hoplonemertea sp. IZ135340 (Ribeira, A Coruña, Galicia, Spain, 14.xii.2010; photo J. Junoy). (M) Tetrastemma sp. IZ-132742 (Cabrera, Balearic Islands, Spain, 29.vii.2012). Additional specimen details can be found in MCZbase (http://mczbase.mcz.harvard.edu/).

Palaeonemertea when analysing $18 \mathrm{~S}$ rRNA data, with some species nesting as the sister group to Heteronemertea while others were the sister species to Hoplonemertea. In line with this finding, Thollesson and Norenburg (2003), on the basis of two nuclear (28S rRNA and histone $\mathrm{H} 3$ ) and two mitochondrial (16S rRNA and cytochrome $c$ oxidase subunit I, COI) genes, recovered a paraphyletic Palaeonemertea as sister group to a clade comprising Heteronemertea and Hoplonemertea
(Neonemertea), with the monogeneric Bdellonemertea nested within monostiliferan hoplonemerteans (the latter placement was also recovered by Sundberg et al. 2001). In contrast to the common finding of a paraphyletic Palaeonemertea, Andrade et al. (2012) employed six markers (28S rRNA, 18S rRNA, histones $\mathrm{H} 3$ and $\mathrm{H} 4,16 \mathrm{~S}$ rRNA and $\mathrm{COI}$ ) and recovered the class (excluding Hubrechtella dubia Bergendal, 1902) as monophyletic, but its placement relative to other classes was 
sensitive to the optimality criterion - under parsimony, the class is the sister group to Hoplonemertea + Hubrechtella dubia, whereas it is the sister group to Heteronemertea under a maximum likelihood approach.

From the limitations of morphological characters has arisen one of the most difficult challenges to deep nemertean phylogenetics: determining the placement of hubrechtiid palaeonemerteans. Based on morphology, Norenburg (1993) suggested an affinity between hubrechtiids and heteronemerteans, and underscored the finding of Cantell (1969) in that Hubrechtella dubia possesses a pilidium larva, a feature that is otherwise exclusive to the class Heteronemertea. However, in a phylogenetic study of Palaeonemertea based solely on morphology, Sundberg and Hylbom (1994) recovered a clade of hubrechtiid taxa nested well within Palaeonemertea - this was later corroborated by phylogenetic analysis of $18 \mathrm{~S}$ rRNA sequences (Sundberg et al. 2001). In contrast, Thollesson and Norenburg (2003) recovered Hubrechtella dubia as the sister group to Heteronemertea, which impelled the authors to erect Pilidiophora, a clade comprising the taxa with a planktotrophic pilidium larva, a pelagic larval type found only within Nemertea, inside which the juvenile forms, eventually undergoing a catastrophic metamorphosis to the adult form (e.g. Maslakova 2010). Employing extensive taxon and data sampling, as well as both maximum likelihood and parsimony approaches, Andrade et al. (2012) found conflicting placements of Hubrechtella dubia depending on the optimality criterion used. Under the maximum likelihood approach, the Pilidiophora hypothesis was recovered (albeit with middling support) whereas parsimony analysis suggested the sister group relationship of Hubrechtella dubia and Hoplonemertea. In a recent investigation into the morphological features of the proboscis of Hubrechtella juliae Chernyshev, 2003, Chernyshev et al. (2013) found similarities between this species and species of Baseodiscus Diesing, 1850 (Heteronemertea), thereby adding to the list of potential synapomorphies for Pilidiophora. Given the above, the Pilidiophora hypothesis remains compelling, but deserves further testing.

The lack of a well-supported and taxon-rich phylogeny of Nemertea has not only limited our knowledge of the interrelationships of the taxa, but also constrained our understanding of their ecological adaptations, such as the mode and timing of nemertean transitions between sea, land and freshwater. Freshwater nemerteans occur in both Hoplonemertea and Heteronemertea, and terrestrial forms are almost unique to Hoplonemertea (Moore and Gibson 1985), and the current discussion on the evolutionary routes taken by nemerteans in their colonisation of freshwater and terrestrial habitats is divided between two main hypotheses (see Moore and Gibson 1985, 1988). The first suggests that marine nemerteans colonised land before a transition to freshwater habitats. This hypothesis is supported by the presence of terrestrial nemerteans on widespread island systems on which freshwater is missing (Moore and Gibson 1985). The second hypothesis is the psammolittoral-phreatic route, in which marine nemerteans, before invading land, have transitioned between fully marine interstitial compartments to the supralittoral zone where saturation of freshwater occurs (Pennak 1963). Moore and
Gibson (1988) suggest that these hypotheses are not mutually exclusive and that it is likely that nemerteans have invaded freshwater and terrestrial habitats on several independent occasions and possibly through different modes of transition, and this is supported also by recent molecular analyses (Andrade et al. 2012).

The present account aims to elucidate four main topics: (i) the general phylogenetic relationships of the phylum in light of a largely increased taxon sampling; (ii) the precise placement of hubrechtiid nemerteans within the largest taxon set assembled for Nemertea by increasing sampling for these elusive nemerteans; (iii) the status and phylogenetic placement of terrestrial and freshwater taxa, with special reference to the family Plectonemertidae; and (iv) the utility of DNA barcoding as a potential tool for rapid and accurate specimen identification across this morphologically challenging phylum.

\section{Materials and methods}

\section{Specimen collection}

Specimens were collected in the field, or obtained from colleagues, and photographed, preserved in $\sim 96 \%$ EtOH and stored in a $-20^{\circ} \mathrm{C}$ freezer at the Museum of Comparative Zoology (MCZ) upon arrival. Collecting details and photographs of selected specimens are available in the MCZ online database (http://mczbase.mcz.harvard.edu), and can be accessed through their catalogue number (Table 1).

\section{DNA extraction, amplification and purification}

Tissue was cut from the most posterior part of each specimen; some specimens were already fragmented and, in such cases, tissue was taken from the posterior part of the fragment (for cf. Ototyphlonemertes pallida IZ-133745, the entire piece of the specimen was used owing to its minute nature). Total genomic DNA was subsequently extracted using the DNeasy Tissue Kit (Qiagen, Valencia, CA) according to the manufacturer's protocol. The remaining parts of the worms are stored as vouchers (except Nemertea sp. SK80, which was sent back to the collectors) at the Museum of Comparative Zoology at Harvard University (Table 1).

Six loci were amplified from the isolates: nuclear $18 \mathrm{~S}$ rRNA, 28S rRNA, histones $\mathrm{H} 3$ and $\mathrm{H} 4$, and mitochondrial 16S rRNA and cytochrome $c$ oxidase subunit I (COI). All primers $(10 \mu \mathrm{M}$ concentration) used for the amplification and sequencing reactions are listed in Table 2. These loci were chosen because they complement the available data for Nemertea, such that these can be analysed in conjunction to the highest extent possible. Amplification used one of two protocols. We first attempted to amplify the DNA using the GoTaq (Promega, Madison, WI, USA) DNA polymerase, with $0.5-1 \mu \mathrm{L}$ DNA template, $0.25 \mu \mathrm{L}$ of forward and reverse primers, $18 \mu \mathrm{L}$ water, $5 \mu \mathrm{L} 5 \mathrm{X}$ Green GoTaq Flexi Buffer and $0.13-0.20 \mu \mathrm{L}$ taq. If unsuccessful, amplifications were carried out using Amplitaq DNA polymerase (Life Technologies, Waltham, MA) with $1 \mu \mathrm{L}$ DNA template, $0.25 \mu \mathrm{L}$ of forward and reverse primers, $20 \mu \mathrm{L}$ water, $2.5 \mu \mathrm{L}$ Buffer I and $0.13-0.20 \mu \mathrm{L}$ taq. The following 
Table 1. Newly sequenced specimens used in the present study with Museum of Comparative Zoology (Harvard University) voucher numbers and their corresponding GenBank accession numbers

Asterisks denote sequences downloaded from GenBank for which the same specimens were used to generate sequences for currently unavailable loci. Note that the below sequences were joined with those of Andrade et al. (2012) to form the final data matrix. Unfortunately, the short nature of the histone $\mathrm{H} 4 \mathrm{sequences}$ prohibits their deposition in GenBank. Therefore, these sequences can be attained from the first author upon request or from TreeBASE submission 14868

\begin{tabular}{|c|c|c|c|c|c|c|c|}
\hline ID & Voucher number & $18 \mathrm{~S}$ & $28 \mathrm{~S}$ & $\mathrm{H} 3$ & $\mathrm{H} 4$ & $16 \mathrm{~S}$ & $\mathrm{COI}$ \\
\hline Carinoma hamanako & IZ-135341 & KF935278 & KF935334 & KF935390 & N/A & KF935446 & KF935500 \\
\hline Cephalothrix bipunctata & IZ-133009 & KF935279 & KF935335 & KF935391 & $\mathrm{N} / \mathrm{A}$ & KF935447 & KF935501 \\
\hline Baseodiscus cf. delineatus & IZ-133729 & KF935280 & KF935336 & KF935392 & N/A & KF935448 & KF935502 \\
\hline Baseodiscus mexicanus & IZ-135321 & KF935281 & KF935337 & KF935393 & N/A & KF935449 & KF935503 \\
\hline Nemertea sp. & SK80 & KF935282 & KF935338 & KF935394 & N/A & & KF935504 \\
\hline Baseodiscus unicolor & IZ-132527 & KF935283 & KF935339 & KF935395 & N/A & KF935450 & \\
\hline Baseodiscus unicolor & IZ-135323 & KF935284 & KF935340 & KF935396 & N/A & KF935451 & KF935505 \\
\hline Baseodiscus unicolor & IZ-135324 & KF935285 & KF935341 & KF935397 & N/A & KF935452 & \\
\hline Micrura ignea & IZ-133720 & KF935286 & KF935342 & KF935398 & N/A & KF935453 & KF935506 \\
\hline Micrura ignea & IZ-135349 & KF935287 & KF935343 & KF935399 & N/A & KF935454 & KF935507 \\
\hline Micrura verrilli & IZ-134451 & KF935288 & KF935344 & KF935400 & $\mathrm{N} / \mathrm{A}$ & KF935455 & KF935508 \\
\hline Micrura sp. & IZ-133724 & KF935289 & KF935345 & KF935401 & N/A & KF935456 & KF935509 \\
\hline Micrura sp. & IZ-132532 & KF935290 & KF935346 & KF935402 & N/A & KF935457 & KF935510 \\
\hline Micrura sp. & IZ-132529 & KF935291 & KF935347 & KF935403 & $\mathrm{N} / \mathrm{A}$ & KF935458 & KF935511 \\
\hline Micrura chlorapardalis & IZ-132530 & KF935292 & KF935348 & KF935404 & N/A & KF935459 & KF935512 \\
\hline Micrura rubramaculosa & IZ-132531 & KF935293 & KF935349 & KF935405 & N/A & KF935460 & KF935513 \\
\hline Micrura dellechiajei & IZ-132745 & KF935294 & KF935350 & KF935406 & $\mathrm{N} / \mathrm{A}$ & KF935461 & KF935514 \\
\hline Notospermus geniculatus & IZ-132741 & KF935295 & KF935351 & KF935407 & N/A & KF935462 & \\
\hline Notospermus sp. & IZ-132528 & KF935296 & KF935352 & KF935408 & N/A & KF935463 & KF935515 \\
\hline Notospermus sp. & IZ-133726 & KF935297 & KF935353 & KF935409 & N/A & KF935464 & \\
\hline Notospermus sp. & IZ-134234 & KF935298 & KF935354 & KF935410 & $\mathrm{N} / \mathrm{A}$ & KF935465 & KF935516 \\
\hline Notospermus sp. & IZ-135356 & KF935299 & KF935355 & KF935411 & N/A & KF935466 & \\
\hline Cerebratulus leucopsis & IZ-135331 & KF935300 & KF935356 & KF935412 & $\mathrm{N} / \mathrm{A}$ & KF935467 & KF935517 \\
\hline Lineus sp. & IZ-132744 & KF935301 & KF935357 & KF935413 & N/A & KF935468 & KF935518 \\
\hline Ramphogordius lacteus & IZ-135373 & KF935302 & KF935358 & KF935414 & N/A & KF935469 & KF935519 \\
\hline Hubrechtella ijimai & IZ-135342 & KF935303 & KF935359 & & & KF935470 & KF935520 \\
\hline Hubrechtidae sp. & IZ-25168 & KF935304 & KF935360 & KF935415 & & KF935471 & KF935521 \\
\hline Reptantia sp. & IZ-132526 & KF935305 & KF935361 & KF935416 & $\mathrm{N} / \mathrm{A}$ & KF935472 & KF935522 \\
\hline Reptantia sp. & IZ-133024 & KF935306 & KF935362 & KF935417 & $\mathrm{N} / \mathrm{A}$ & KF935473 & KF935523 \\
\hline Amphiporidae sp. & IZ-132746 & KF935307 & KF935363 & KF935418 & N/A & KF935474 & \\
\hline Nemertea sp. & IZ-132533 & KF935308 & KF935364 & KF935419 & N/A & KF935475 & KF935524 \\
\hline Argonemertes sp. & IZ-135315 & KF935309 & KF935365 & KF935420 & $\mathrm{N} / \mathrm{A}$ & KF935476 & KF935525 \\
\hline Plectonemertidae sp. & IZ-25166 & KF935310 & KF935366 & KF935421 & & KF935477 & KF935526 \\
\hline Plectonemertidae sp. & IZ-25167 & KF935311 & KF935367 & & & KF935478 & KF935527 \\
\hline Plectonemertidae sp. & IZ-25169 & KF935312 & KF935368 & KF935422 & & KF935479 & KF935528 \\
\hline Plectonemertidae sp. & IZ-25173 & KF935313 & KF935369 & KF935423 & N/A & KF935480 & KF935529 \\
\hline Plectonemertidae sp. & IZ-25174 & KF935314 & KF935370 & KF935424 & $\mathrm{N} / \mathrm{A}$ & KF935481 & KF935530 \\
\hline Plectonemertidae sp. & IZ-25175 & KF935315 & KF935371 & KF935425 & $\mathrm{N} / \mathrm{A}$ & KF935482 & KF935531 \\
\hline cf. Potamonemertes percivali & IZ-25172 & KF935316 & KF935372 & KF935426 & N/A & KF935483 & KF935532 \\
\hline Monostilifera sp. & IZ-133023 & KF935317 & KF935373 & KF935427 & $\mathrm{N} / \mathrm{A}$ & KF935484 & KF935533 \\
\hline Plectonemertidae sp. & NT000046 & EU255585* & & KF935428 & & & EU255614* \\
\hline Plectonemertidae sp. & NT000059 & EU255592* & & KF935429 & & KF935485 & EU255621* \\
\hline Plectonemertidae sp. & NT000072 & EU255596* & & & & KF935486 & EU255626* \\
\hline Tetranemertes antonina & IZ-132747 & KF935318 & KF935374 & KF935430 & N/A & & KF935534 \\
\hline Oerstedia $\mathrm{sp}$. & IZ-132740 & KF935319 & KF935375 & KF935431 & N/A & KF935487 & KF935535 \\
\hline Oerstedia sp. & IZ-132743 & KF935320 & KF935376 & KF935432 & N/A & KF935488 & KF935536 \\
\hline Antarctonemertes valida & IZ-134228 & KF935321 & KF935377 & KF935433 & N/A & KF935489 & KF935537 \\
\hline Antarctonemertes riesgoae & IZ-134229 & KF935322 & KF935378 & KF935434 & N/A & KF935490 & KF935538 \\
\hline Tetrastemma vititgera & IZ-132742 & KF935323 & KF935379 & KF935435 & $\mathrm{N} / \mathrm{A}$ & KF935491 & KF935539 \\
\hline Tetrastemma vittigera & IZ-25171 & KF935324 & KF935380 & KF935436 & N/A & & KF935540 \\
\hline Tetrastemma sp. & IZ-132742 & KF935325 & KF935381 & KF935437 & N/A & KF935492 & KF935541 \\
\hline Tetrastemmatidae & IZ-132537 & KF935326 & KF935382 & KF935438 & N/A & KF935493 & KF935542 \\
\hline Hoplonemertea sp. & IZ-135340 & KF935327 & KF935383 & KF935439 & N/A & KF935494 & KF935543 \\
\hline Vietezia luzmurubeae & IZ-133740 & KF935328 & KF935384 & KF935440 & $\mathrm{N} / \mathrm{A}$ & KF935495 & KF935544 \\
\hline cf. Ototyphlonemertes pallida & IZ-133745 & KF935329 & KF935385 & KF935441 & $\mathrm{N} / \mathrm{A}$ & KF935496 & KF935545 \\
\hline
\end{tabular}


Table 1. (continued)

\begin{tabular}{|c|c|c|c|c|c|c|c|}
\hline ID & Voucher number & $18 \mathrm{~S}$ & $28 \mathrm{~S}$ & $\mathrm{H} 3$ & $\mathrm{H} 4$ & $16 \mathrm{~S}$ & $\mathrm{COI}$ \\
\hline Amphiporus formidabilis & IZ-134452 & KF935331 & KF935387 & KF935443 & N/A & KF935498 & KF935547 \\
\hline Geonemertes sp. & IZ-132534 & KF935333 & KF935389 & KF935445 & $\mathrm{N} / \mathrm{A}$ & KF935499 & KF935548 \\
\hline
\end{tabular}

Table 2. List of primers used in the present study

Forward primer sequences are denoted in bold font. For $28 \mathrm{~S}$, the reverse primer rd4b was used with rd1a only when the primer set rd1a/b failed to amplify

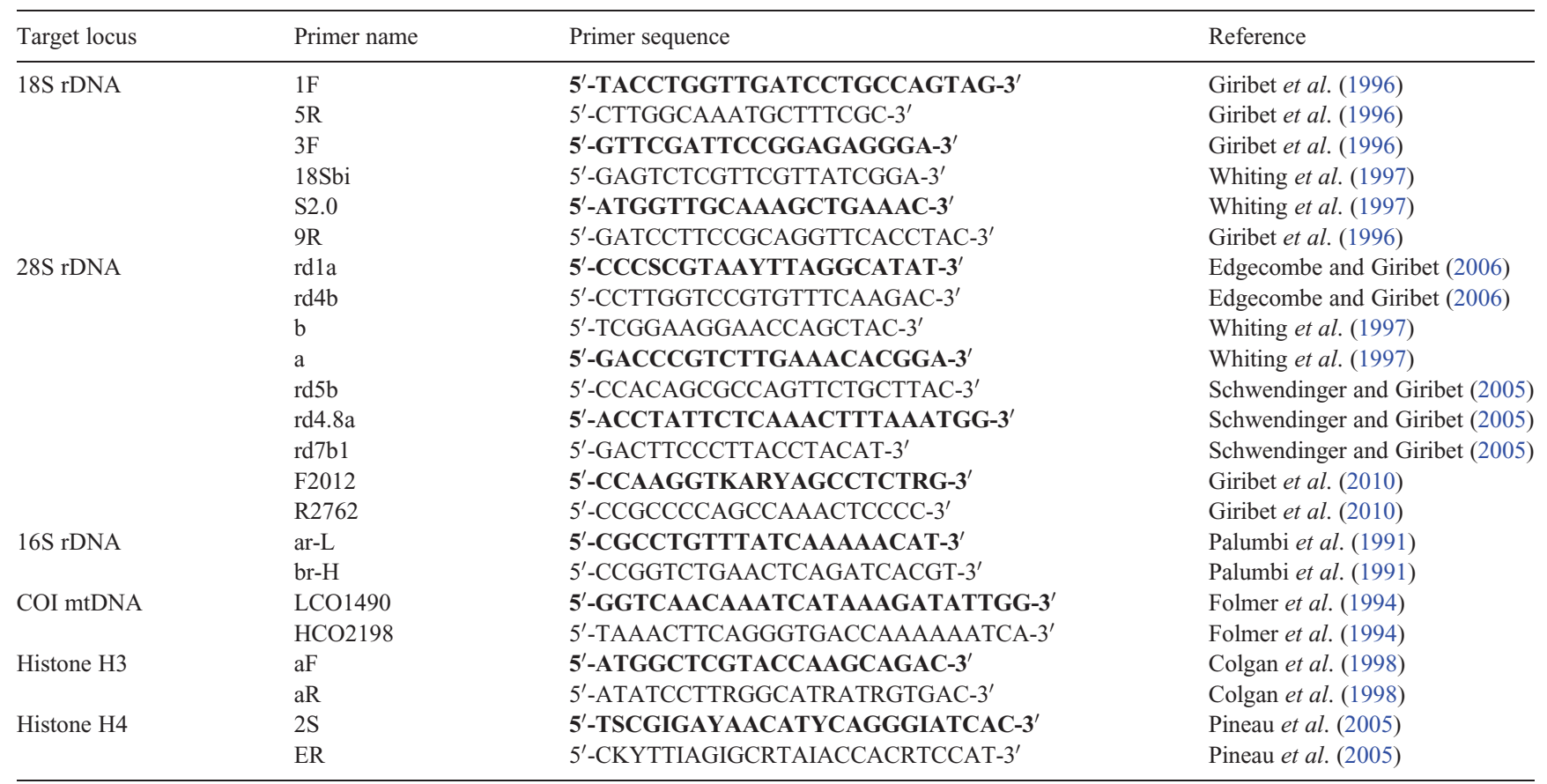

thermal profiles were used for the PCR amplifications: 2 min initial denaturation at $94^{\circ} \mathrm{C}$ for all samples followed by $30-35$ cycles of $30 \mathrm{~s}$ denaturation at $94^{\circ} \mathrm{C}, 30-60 \mathrm{~s}$ annealing at $45-48^{\circ} \mathrm{C}$, $1 \mathrm{~min}$ extension at $72^{\circ} \mathrm{C}$; all reactions were completed with a final extension step for $10 \mathrm{~min}$ at $72^{\circ} \mathrm{C}$. Polymerase chain reaction (PCR) products were then visualised on a $1 \%$ agarose gel and purified using ExoSAP-IT (USB Corp, Cleveland, $\mathrm{OH}$ ) following manufacturer's protocols. Purified products were cycle-sequenced using the same primers as for the amplifications and the following reagents: $3.2 \mu \mathrm{L}$ sequencing primer $(0.5 \mu \mathrm{M}), 4.8 \mu \mathrm{L}$ water, $1 \mu \mathrm{L}$ purified DNA template, $0.5 \mu \mathrm{L}$ ABI BigDye $5 \times$ sequencing buffer, and $0.5 \mu \mathrm{L}$ ABI BigDye Terminator ver. 3.1 (Applied Biosystems, Foster City, CA) for a total volume of $10 \mu \mathrm{L}$. Cycle-sequencing products were further cleaned using Sephadex G-50 (GE Healthcare, Piscataway, NJ) columns and later sequenced using an ABI Prism 3730 Genetic Analyzer (Applied Biosystems).

\section{Alignment and phylogenetic analysis}

Forward and reverse sequences were assembled, and the contigs manually edited using Sequencher ver. 5.1 (Gene Codes Corporation, Ann Arbor, MI). Prior to alignment,
BLASTn searches against the NCBI nr database were carried out for each sequence to control for potential contaminations.

In order to increase the taxon sampling and thereby more robustly infer the phylogenetic relationships, the newly generated dataset was then combined with that used by Andrade et al. (2012), both datasets having targeted the same markers. Multiple sequence alignments were carried out separately for each locus using MAFFT ver. 7 (Katoh and Standley 2013), and employing the L-INS-i strategy (recommended for sequences with one conserved domain and flanking gaps) for COI, histones H3 and H4, and the E-INS-i strategy (recommended for sequences with multiple conserved domains and interspersed gaps) for the ribosomal $18 \mathrm{~S}, 28 \mathrm{~S}$ and $16 \mathrm{~S}$ rRNAs. The alignments used the following settings: 1.53 gap opening penalty for $16 \mathrm{~S}$ rRNA, COI, and histones $\mathrm{H} 3$ and H4; 3.00 gap opening penalty for $18 \mathrm{~S}$ rRNA and $28 \mathrm{~S}$ rRNA; the $200 \mathrm{PAM} / \mathrm{K}=2$ scoring matrix and an offset value of 0.0 . From this, three different datasets were constructed in Mesquite ver. 2.5 (Maddison and Maddison 2010): the first including all of the newly generated data, as well as those of Andrade et al. (2012); the second including the same data but masking the hypervariable regions of $18 \mathrm{~S}$ rRNA and $28 \mathrm{~S}$ rRNA by employing the web version of Gblocks ver. $0.91 \mathrm{~b}$ (Castresana 
2000) (for this purpose, we allowed smaller final blocks, gap positions within the final blocks, less strict flanking positions but we did not allow many contiguous non-conserved positions); and the third including COI, histone H3, 16S rRNA and 18S rRNA sequences exclusively for Hubrechtidae and Hoplonemertea with the addition of four terrestrial taxa for which both GenBank sequences and unpublished sequences were used. These were Antiponemertes novaezealandiae (Dendy, 1895) (18S rRNA: AY928345), Acteonemertidae NT000046 (COI: EU255614, 18S rRNA: EU255585, histone H3: unpublished, 16S rRNA: unpublished), Acteonemertidae NT000059 (COI: EU255621, 18S rRNA: EU255592, histone H3: unpublished, 16S rRNA: unpublished), and Acteonemertidae NT000072 (COI: EU255626, 18S rRNA: EU255596, histone H3: unpublished, 16S rRNA: unpublished). The final data matrices and trees are available from TreeBASE under submission 14868.

Maximum likelihood (ML) and maximum parsimony (MP) analyses were then used to reconstruct the phylogenetic relationships. Prior to the ML analysis, optimal partitioning schemes and best-fitting models of nucleotide evolution (restricting the search to GTR and GTR $+\Gamma$ ) were identified for each dataset using PartitionFinder ver. 1.1.1 (Lanfear et al. 2012). PartitionFinder uses an heuristic algorithm (here we used the 'greedy' algorithm), beginning with a user-provided fully partitioned dataset (i.e. partitioned by locus and codon position, when appropriate) and identifies the best-fitting partitioning scheme by likelihood tests using a predetermined selection criterion (in this case the Bayesian information criterion). Employing the best partitioning scheme, an heuristic search was performed using RAxML ver. 7.6.3 (Stamatakis 2006) on the CIPRES Science Gateway platform (Miller et al. $2010)$ with a GTR $+\Gamma$ model of sequence evolution for all partitions, and consisting of 1000 iterations with 25 initial GAMMA rate categories and final optimisation with four GAMMA shape categories (RAxML was called as follows: raxmlHPC-HYBRID -T 6 -s infile -n result -q part -p 12345 m GTRGAMMA -o Terebratalia_transversa -f d -N 1000). Standard bootstrap support values were calculated using 1000 pseudoreplicates with a different starting tree for each iteration.

For MP, a new technology search was performed using TNT (Goloboff et al. 2008). Trees were recovered by using 1000 initial addition sequences, five rounds of ratcheting and three rounds of tree fusing after the initial Wagner tree builds, and requiring that the minimum length tree be found a total of 10 times before terminating the search. Using the command 'bbreak', trees resulting from the new technology search were then returned to TNT for TBR branch swapping. All characters were equally weighted and non-additive, and gaps were treated as missing data to use the same information employed in the probabilistic analyses. Bootstrap support was calculated from 1000 pseudoreplicates with the same settings as mentioned above. All trees were rooted at Terebratalia transversa (Sowerby, 1846) (Brachiopoda) following Andrade et al. (2012).

\section{Tree constraints}

Likelihood-based Shimodaira-Hasegawa (SH; Shimodaira and Hasegawa 1999) and approximately unbiased tests (AU;
Shimodaira 2002) were carried out to assess statistical differences between a posteriori topological hypotheses of the completely unconstrained (i.e. the maximum likelihood) tree and a tree in which Hubrechtidae + Heteronemertea were forced to form a monophyletic group (Pilidiophora). Both $\mathrm{SH}$ and AU tests use nonparametric bootstrap resampling of estimated sitewise log-likelihood scores to assess the statistical significance (in a frequentist framework) of differences in likelihood scores between user-constrained phylogenetic trees, usually including the ML tree. The SH test is more conservative than the AU test, but this behaviour is most problematic only when many tree topologies are compared (Shimodaira 2002). Per site log-likelihood values (which summed constitute the log-likelihood of a phylogram) were calculated in RAxML using the '-f g' option (RAxML was called as follows: raxmlHPC-HYBRID -T 6 -s input_file - n results -p 12345 -m GTRGAMMA -f g -z best_constrained_tree) and these were subsequently submitted to CONSEL (Shimodaira and Hasegawa 2001) for statistical analysis under default parameters. Statistical significance $(p \leq 0.05)$ was calculated based on the best-scoring unconstrained and constrained RAxML trees; because CONSEL does not consider partitions when performing resampling of sitewise log-likelihoods, the site likelihood values were derived from an unpartitioned analysis. In addition, an analysis forcing the monophyly of Pilidiophora was also performed for parsimony, using the 'force +' command in TNT; the number of extra steps needed to enforce the constraint were then counted.

\section{Barcoding gap detection}

To investigate the presence of a phylum-wide barcoding gap for Nemertea, all COI sequences connected to a binomial taxonomic label in GenBank were downloaded. Imprecise taxon labels (e.g. Cerebratulus sp.) were discarded to increase the certainty of comparing the same species in the intraspecific analyses and different species in the interspecific analyses. That is, in order to solidly infer intraspecific variations and interspecific divergences, we needed to know the exact taxonomic affiliations of the sequences - although the rate of erroneous identifications in nemerteans and other soft-bodied worms tends to be high. In addition, all sequences less than $200 \mathrm{bp}$ long were removed from the dataset. The COI sequences downloaded from GenBank were combined with the newly generated COI sequences for which species level identifications were available and these were jointly aligned using MAFFT L-INS-i applying default gap opening costs. In four cases, MAFFT detected reverse complementation of sequences (this is an automated feature of version 7 when performing the analyses online at http://mafft.cbrc.jp/ alignment/server/) and these were therefore reversed using the sequence manipulation suite (Stothard 2000). MEGA ver. 5 (Tamura et al. 2011) was used to calculate intraspecific variations and interspecific divergences among the samples using the following settings: uncorrected $p$-distances, uniform rates among sites and pairwise deletion of gaps for first, second and third codon positions.

Complementary to this, automatic barcode gap discovery (ABGD; Puillandre et al. 2012) was employed to verify the 
distribution and size of a potential barcoding gap. Automatic barcode gap discovery was applied using default settings $(\operatorname{pmin}=0.001, \operatorname{pmax}=0.1$, steps $=10$, and Jukes-Cantor [JC69] distances). A neighbour-joining tree was also constructed by MEGA ver. 5 for the full COI dataset, using uncorrected $p$-distances and applying mid-point rooting.

\section{Results}

In total, 56 specimens were newly sequenced for $18 \mathrm{~S}$ rRNA, $28 \mathrm{~S}$ rRNA, histones $\mathrm{H} 3$ and $\mathrm{H} 4,16 \mathrm{~S}$ rRNA and $\mathrm{COI}$; three additional plectonemertid specimens were sequenced for histone $\mathrm{H} 3$ and 16S (18S rRNA and COI are already available for these taxa; see Table 1), and Antarctonemertes riesgoae Taboada, Junoy, Andrade, Giribet, Cristobo \& Avila, 2013 and A. valida (Bürger, 1893) were newly sequenced for parts of 28S rRNA and histones $\mathrm{H} 3$ and $\mathrm{H} 4$ (partial 28S rRNA, 16S rRNA and COI was already available for these taxa; see Table 1). All molecular sequences that were newly generated for the present study have been deposited in GenBank under accession numbers KF935278-KF935548 (Table 1), with the exception of histone $\mathrm{H} 4$ whose short sequence length prohibits their deposition in GenBank. The histone H4 sequences are therefore available from the first author upon request or from TreeBASE submission number 14868. The total number of aligned sites for the full dataset after inclusion of the data used by Andrade et al. (2012) was 8706 (18S rRNA: 2238 bp; 28S rRNA: 4615 bp; histone H3: 341 bp; histone H4: 166 bp; 16S rRNA: 681 bp; COI: 665 bp). For the alignment treated with Gblocks, the corresponding number was 4946 aligned sites (18S rRNA: 1650 bp; $28 \mathrm{~S}$ rRNA: $1479 \mathrm{bp}$; histone H3: $341 \mathrm{bp}$; histone H4: $166 \mathrm{bp} ; 16 \mathrm{~S}$ rRNA: 645 bp; COI: 665 bp). The extended hoplonemertean alignment, including four taxa for which sequences were downloaded from GenBank, comprised 3599 aligned sites (18S rRNA: 2030 bp; histone H3: 335 bp; 16S rRNA: 576 bp; COI: 658 bp).

\section{Phylogeny - full dataset}

The heuristic ML search of the full six-marker partitioned dataset produced a tree with an $\ln L$ of -195608.806782 (Fig. 3). Bootstrap values are rather low across the topology, especially in the deeper nodes. In the tree, Nemertea is recovered as monophyletic but with low likelihood bootstrap support (LBS: 54). As in previous studies, Palaeonemertea is recovered as paraphyletic with Carinoma Oudemans, 1885 species + Carinina ochracea Sundberg, Chernyshev, Kajihara, Kånneby \& Strand, 2009 (LBS: 89) and the remaining tubulanids + cephalothricids (LBS: 85) forming two consecutive clades with Carinoma spp. $+C$. ochracea as the earliest diverging lineage, sister group to the remaining nemerteans (LBS: 85). The monophyly of Heteronemertea received maximum support (LBS: 100) and the class nests as the sister group to Hubrechtidae + Hoplonemertea (LBS: 65), and both of the latter are also reciprocally monophyletic and maximally supported.

Within the paraphyletic Palaeonemertea, Callinera grandis Bergendal, 1903 nests within Tubulanus Renier, 1804 rendering the genus paraphyletic (LBS: 100), whereas Cephalothricidae is recovered as its monophyletic (LBS: 100) sister group.
Within Heteronemertea, the included specimens of Baseodiscus are recovered as a clade (LBS: 89), as the sister group to the remaining heteronemerteans. Much like in the tree produced by Andrade et al. (2012), numerous heteronemertean genera are rendered non-monophyletic. For example, the included species of Micrura Ehrenberg, 1871 are recovered in six separate places in the tree (see also Schwartz and Norenburg 2005): the three specimens of Micrura ignea Schwartz \& Norenburg, 2005 (monophyletic with LBS: 100) are the sister species to the remaining non-Baseodiscus heteronemerteans (LBS: 55); a clade comprising Micrura verrilli Coe, 1901 and three undetermined Micrura species (LBS: 77) nest on a consecutive branch to Micrura ignea, as sister group to the remaining taxa (LBS: 95); Micrura dellechiajei (Hubrecht, 1879) appears as the sister group to three specimens of Notospermus Huschke, 1829 (LBS: 95); Micrura chlorapardalis Schwartz \& Norenburg, 2005 groups with Micrura rubramaculosa Schwartz \& Norenburg, 2005 (LBS: 100) as sister clade to Cerebratulus marginatus Renier, 1804 (LBS: 78); and Micrura purpurea (Dalyell, 1853) nests as sister species to a clade (LBS: 73) containing Parborlasia corrugatus (McIntosh, 1876), the monophyletic Micrura fasciolata Ehrenberg, 1828 (LBS: 100), the two paraphyletic genera Lineus Sowerby, 1806 and Ramphogordius Rathke, 1843, and the monophyletic Riseriellus occultus Rogers, Junoy, Gibson \& Thorpe, 1993 specimens (LBS: 100).

The three hubrechtiid specimens form a clade (LBS: 100) sister to Hoplonemertea (LBS: 100), which, in turn, splits into Polystilifera (LBS: 100) and Monostilifera (LBS: 100). Interestingly, a clade of terrestrial and freshwater hoplonemerteans is recovered with high bootstrap support (LBS: 100) (see below and 'Discussion'). This clade includes Argonemertes australiensis (Dendy, 1892), Leptonemertes cf. chalicophora (Graff, 1879), cf. Potamonemertes percivali Moore \& Gibson, 1973, and four undescribed plectonemertid species from Australia.

The strict consensus of nine equally parsimonious trees (length: 42678 steps; consistency index (CI): 0.253; retention index (RI): 0.610) produced by TNT (Fig. 4) for the same dataset is highly congruent with that of the ML analysis, albeit with minor differences in the detailed placement of some taxa. Overall, however, support values associated with the parsimony tree are relatively lower than those of the ML tree. Palaeonemertea is again recovered as paraphyletic, but in this tree, the Tubulanus + Callinera and Cephalotricidae clade (parsimony bootstrap support (PBS): 69) is recovered as the earliest diverging lineage (PBS: 98). The remaining major lineages are recovered as monophyletic; Heteronemertea with PBS: 100; Hubrechtidae with PBS: 100; Hoplonemertea with PBS: 99; Polystilifera with PBS: 100; and Monostilifera with PBS: 99).

Both the SH test and AU test agree that the unconstrained tree and the tree forced to show a monophyletic Pilidiophora are statistically different ( $p=0.00$ and $p=3 \mathrm{E}^{-64}$, respectively). However, the constrained parsimony analysis resulted in nine equally parsimonious trees (not shown) with 42686 steps (CI: 0.253; RI: 0.610); only eight extra steps ( $\sim 0.02 \%$ of total tree length) were needed to invoke a monophyletic Pilidiophora. 


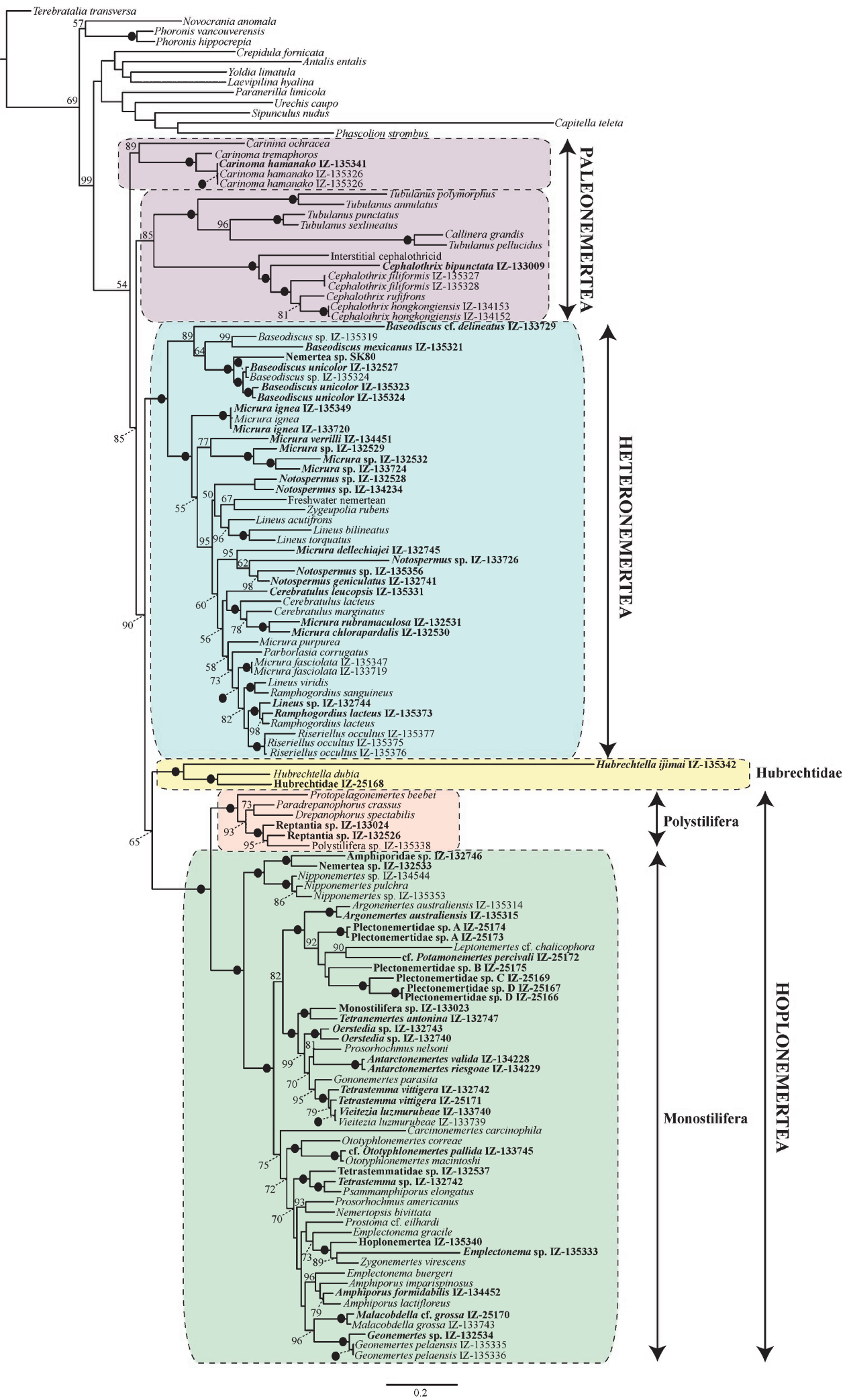

Fig. 3. Best scoring tree from the maximum likelihood analysis of the full six-marker dataset $(\ln L=-195608.806782)$. Likelihood bootstrap values $>50 \%$ are shown above each node and solid circles indicate full bootstrap support. Specimens sequenced for the present study are denoted in bold font and IZ numbers refer to the morphological voucher ID deposited in the Department of Invertebrate Zoology collection of the MCZ. 


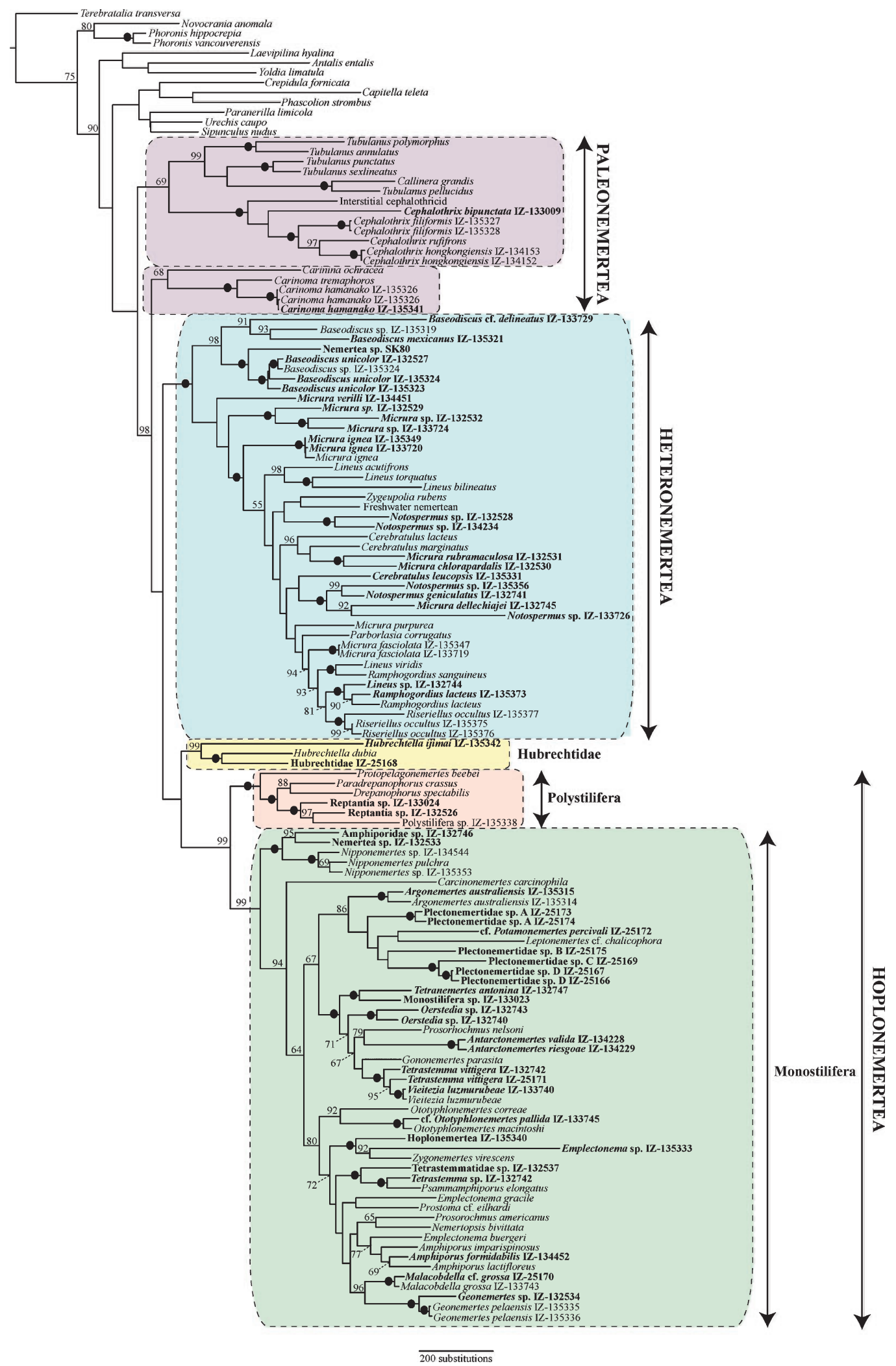

Fig. 4. Strict consensus of nine equally parsimonious trees (length: 42678 steps; consistency index: 0.253; retention index: $0.610)$ produced by TNT for the full six-marker dataset. Legends as in Fig. 3. 


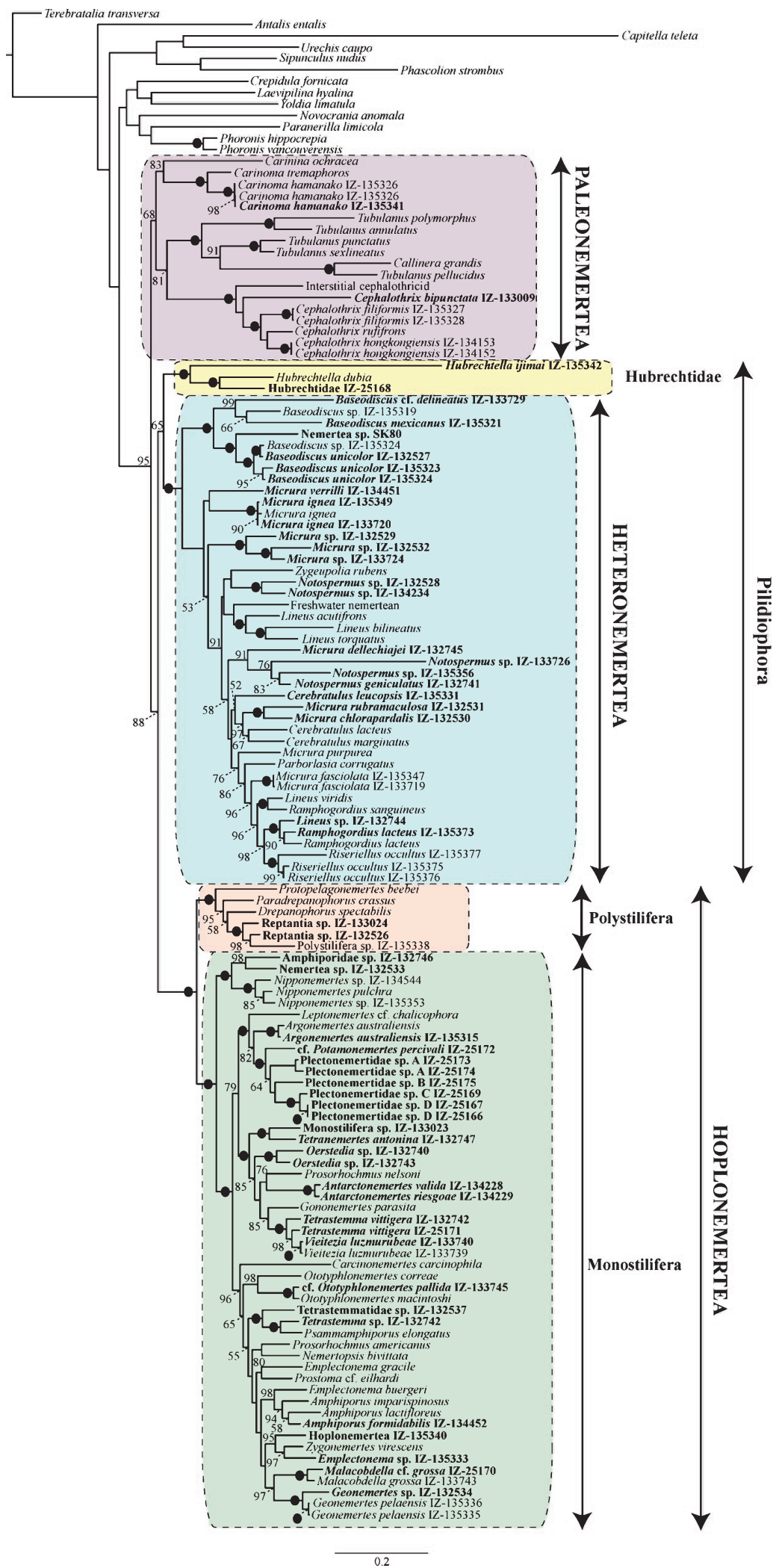

Fig. 5. Best scoring tree from the maximum likelihood analysis of the six-marker dataset with hypervariable regions removed by Gblocks $(\ln L=-122882.420713)$. Legends as in Fig. 3 . 


\section{Phylogeny - Gblocks-trimmed dataset}

The ML analysis of the dataset with variable regions removed by Gblocks returned a tree with a $\ln L$ of -122882.420713 (Fig. 5). The resulting tree is highly congruent with that of the full dataset concerning the intrafamilial relationships, but some discrepancies do exist between the trees. Most importantly, in the ML Gblocks tree Palaeonemertea is recovered as a monophyletic (LBS: 68) sister group to the remaining nemerteans (LBS: 88). In addition, the Pilidiophora hypothesis is supported (LBS: 65) as Hubrechtidae (monophyletic with LBS: 100) is recovered as sister group to Heteronemertea, as opposed to Hoplonemertea for the full dataset. Each class is recovered as monophyletic with high support, and the plectonemertid clade is again recovered as monophyletic (LBS: 100) but with a slightly different internal topology compared with the tree of the full dataset.

The single most parsimonious tree recovered by TNT (length: 26238 steps; CI: 0.223; RI: 0.601) is again largely compatible with the ML tree, but displays an overall decrease in bootstrap values (Supplementary Fig. S1). As opposed to the ML tree, however, Palaeonemertea is recovered as paraphyletic in the MP tree, with the Tubulanidae + Cephalothricidae clade as sister group to the larger clade including Hubrechtidae, Heteronemertea and Hoplonemertea. Hubrechtidae is recovered as sister group to Heteronemertea but with low bootstrap support (PBS: <50).

\section{Phylogeny - Hoplonemertea}

Maximum likelihood analysis of the four-marker extended hoplonemertean dataset, including four additional terrestrial taxa for which sequences were downloaded from GenBank, resulted in a tree with a $\ln L$ of -41886.101242 (Fig. 6). Polystilifera and Monostilifera are both monophyletic with maximum support and the four additional terrestrial taxa nest within the plectonemertid clade (LBS: 97) that was also recovered in the analyses of the full dataset and in the dataset treated with Gblocks. Within this clade, an unidentified plectonemertid species from Spain (NT000059) (see Mateos and Giribet 2009) is weakly recovered as the sister species to the remaining taxa (LBS: <50), which are further divided into four main subclades: the first including the Argonemertes australiensis specimens (LBS: 99); the second including two unidentified plectonemertid specimens (NT000072 and NT000046; LBS: 100; see Mateos and Giribet 2009); the third including Antiponemertes novazealandiae and Leptonemertes cf. chalicophora (LBS: 99); and the fourth comprising the remaining undescribed Australian plectonemertid taxa and cf. Potamonemertes percivali (LBS: 100).

The MP analysis of the same dataset resulted in two equally parsimonious trees with 8918 steps (CI: 0.299; RI: 0.503). The strict consensus of these (Supplementary Fig. S2) is relatively unresolved but does not conflict with the ML tree. Regarding Plectonemertidae, the exact same topology as the ML tree was recovered by the MP analysis and with high support (PBS between 82 and 100) for the same subclades.

\section{Barcoding gap detection}

The full COI dataset, including all sequences from GenBank that were associated with a binomial taxonomic label, comprised
394 terminals with 137 unique taxonomic labels (i.e. putatively different species); the multiple sequence alignment comprised 674 sites. In total, 9452 interspecific and 4453 intraspecific variation values were compared (these are fully presented in Supplementary Tables 1 and 2); the average interspecific uncorrected $p$-distance within the entire dataset was $19.61 \% \pm 3.58 \quad(\max =40.13 \% ; \quad \min =0.10 \%) \quad$ and the average intraspecific variation was $1.14 \% \pm 2.87$ ( $\max =$ $20.87 \%$; $\min =0.00 \%$ ). The uncommonly low minimum interspecific distance and uncommonly high maximum intraspecific distance are discussed further below. In total, 3827 out of the 4453 intraspecific comparisons (86\%) showed distances below $1 \%$, and 3937 (88\%) showed distances below $2 \%$. Moreover, fully 9444 out of the 9452 interspecific comparisons (99.9\%) showed distances above 2\%, with 9422 comparisons $(99.6 \%)$ showing distances of $10 \%$ or higher. Fig. 7 shows the distribution of interspecific versus intraspecific values across the full dataset and the figure indicates that there is an absence of a fully discrete and sufficiently sized barcoding gap, although a tendency towards separation of maximum intraspecific variation and minimum interspecific divergence is present. Contrary to this, the results from the ABGD show a distinct disjunction between what is presumed by the software to be intraspecific variation $(\sim 2 \%)$ and interspecific divergence $(\sim 8 \%)$ (Fig. $8 A)$. This is likely a result of ABGD's a priori assumption of the distribution of genetic variation within the dataset, seeing as several of the empirical intraspecific variation values from the dataset exceed the lower limit of the interspecific divergence recovered by ABGD. In other words, the results from ABGD could easily have been misinterpreted to suggest the presence of a relatively large barcoding gap, had the empirical values not been calculated. The 'gap' depicted by ABGD is, in fact, flanked by intraspecific distance values on both sides. Note that this does not necessarily diminish the value of ABGD but, rather, suggest the difficulty of inferring species level identifications for nemerteans (discussed further below).

As a corroborative element to this, we investigated the topology, with special attention to branch lengths, of the neighbour-joining tree derived from the same 394-terminal dataset. At first glance, the tree (Fig. 9) suggests a large length difference between branches that connect conspecifics and those that connect non-conspecifics. That is, branches linking sister groups of different species are much longer than those terminal branches that link the same species. After considering the detailed positions of the different species in the tree, however, it is evident that several specimens with the same taxonomic label (e.g. Cerebratulus leucopsis (Coe, 1901), Lineus bilineatus (Renier, 1804) and Tetrastemma vermiculus (Quatrefages, 1846); see Fig. 9) are present in several remote places in the tree. There seems to be little tendency towards clustering of taxonomic groups in the tree, although some clusters of specimens from the same group do exist. For example, a large cluster of specimens belonging to Cephalothricidae is present in the tree (a second cluster of three specimens of Cephalothrix major Coe, 1930 exists in a separate part of the tree; not shown), and specimens of Malacobdella Blainville, 1827 group together in the tree, and so do the specimens of Tetrastemma Ehrenberg, 1831. 


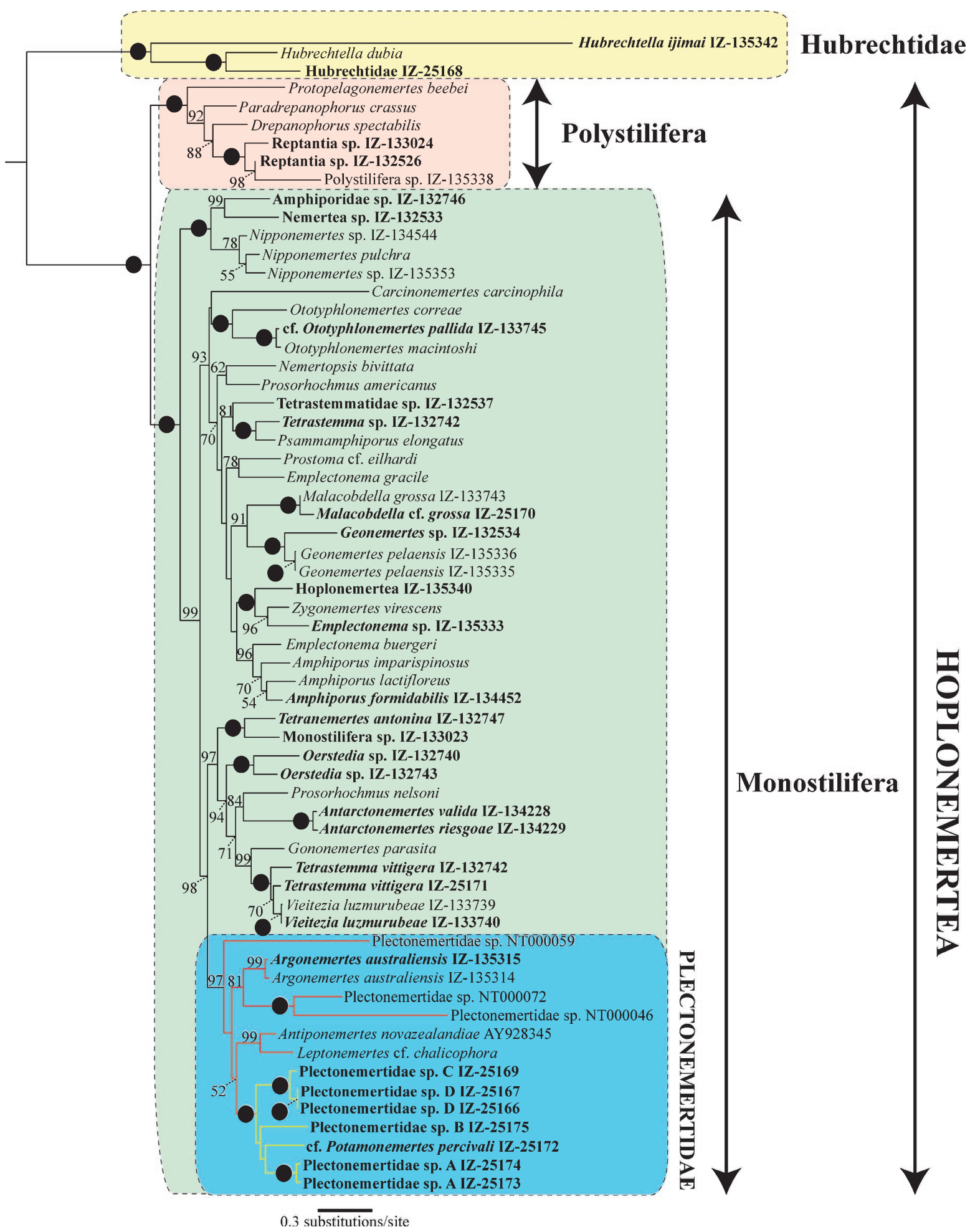

Fig. 6. Best scoring tree from the maximum likelihood analysis of the extended hoplonemertean dataset with sequence data for four taxa added from GenBank $(\ln L=-41886.101242)$. Legends as in Fig. 3. Within the plectonemertid clade, red and yellow branches lead to terrestrial and freshwater taxa, respectively. 


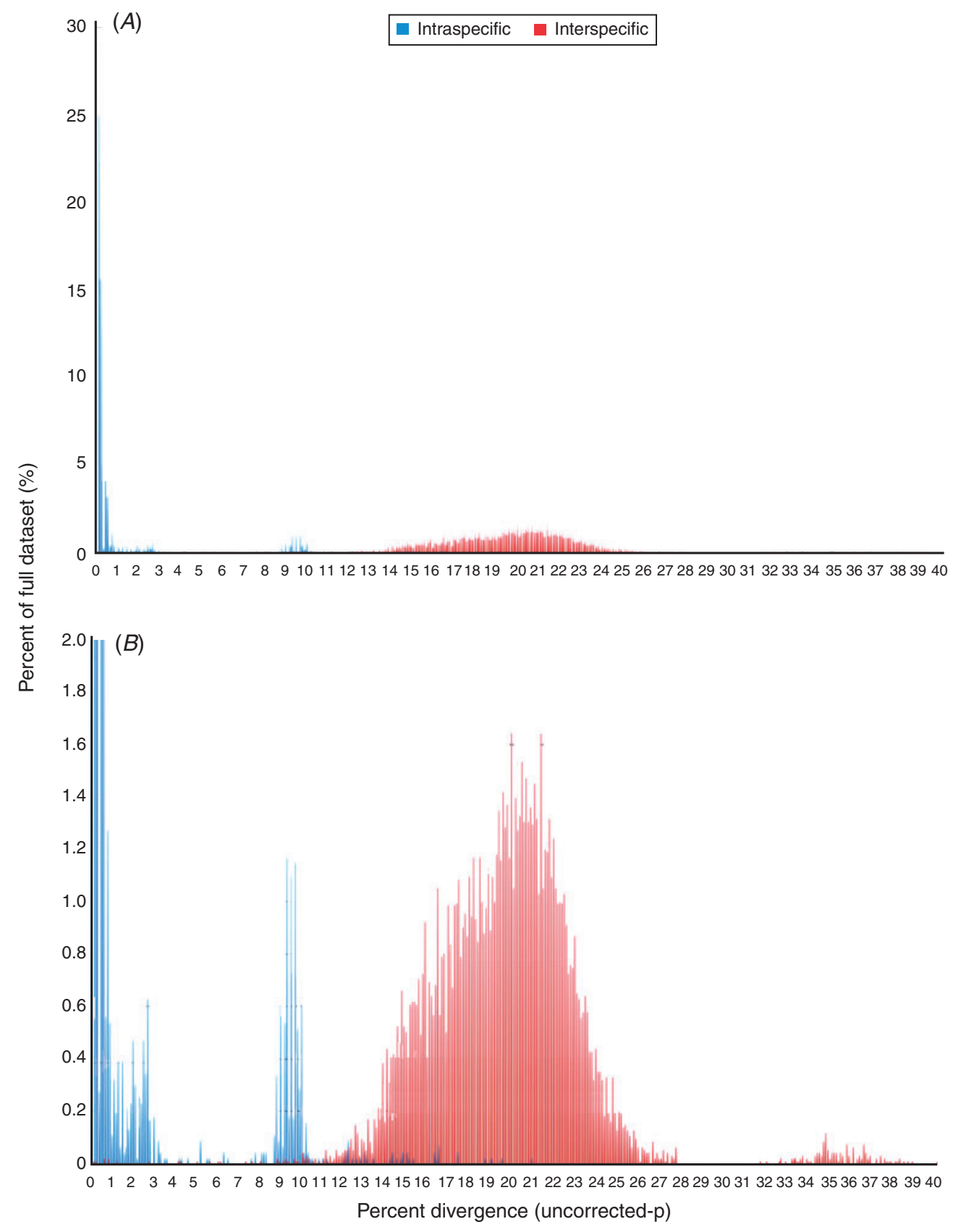

Fig. 7. The distribution of interspecific versus intraspecific distance values across the full COI dataset for Nemertea $(n=394)$. (A) Chart showing the entire range of the $y$-axis; $(B)$ enlarged view of the full dataset with the $y$-axis set to a maximum of $2 \%$. Blue bars indicate intraspecific variation and red bars indicate interspecific divergences.

\section{Discussion}

Employing the largest gene and taxon sampling to date for nemertean taxa, the phylogenetic hypotheses presented here agree well with previous hypotheses, especially concerning the phylogenetic status and inter-relationships of higher taxonomic ranks. In three out of the four analyses that employed the full taxon dataset, Palaeonemertea (excluding Hubrechtidae) is recovered as paraphyletic; only the ML analysis of the dataset with hypervariable regions removed recovered the class as monophyletic (again, excluding Hubrechtidae). This result mirrors that of Sundberg et al. (2001) and Thollesson and Norenburg (2003), but contradicts the topology recovered by Andrade et al. (2012) in which Palaeonemertea was recovered as monophyletic (but always with negligible support) regardless of optimality criterion and alignment masking. Beyond this, the trees recovered here support previous morphological and molecular hypotheses insofar as each of Heteronemertea, Hoplonemertea, Polystilifera, Monostilifera and Hubrechtidae are monophyletic. A basal split between 

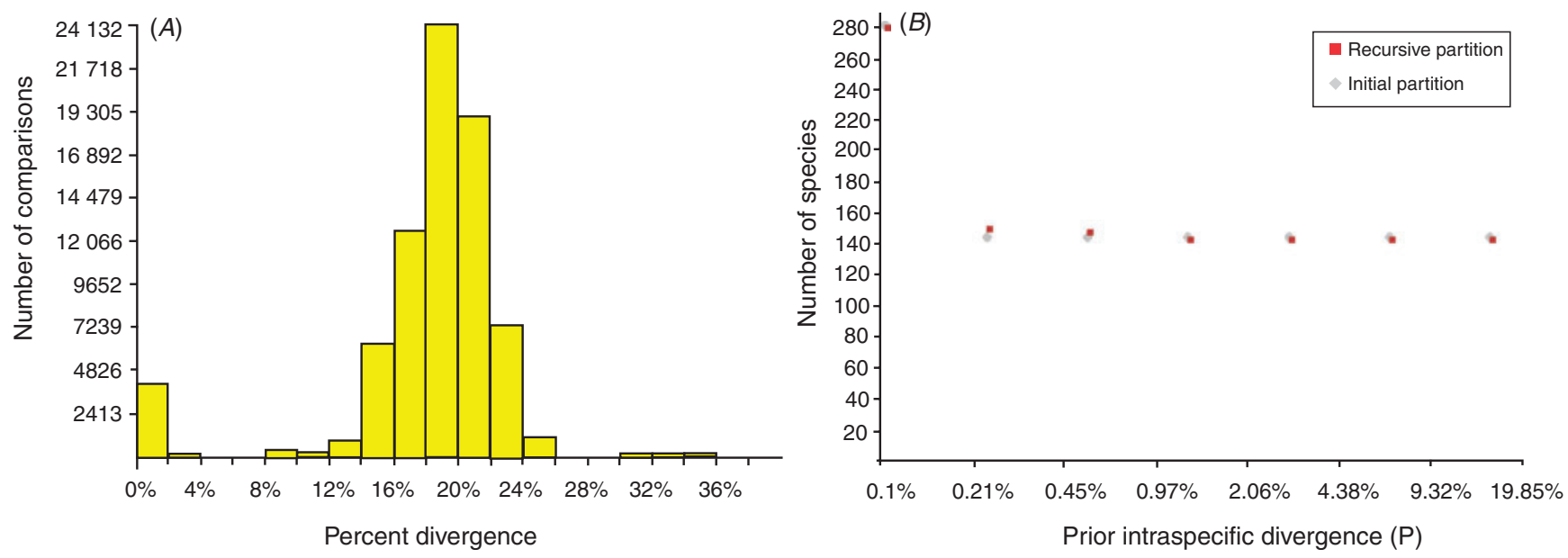

Fig. 8. Schematic illustrations of the results from the automatic barcode gap discovery software. $(A)$ Histogram of distances with the distribution showing two modes. Without prior knowledge of the taxonomic labels associated with each comparison, the figure suggests the presence of a barcoding gap between $~ 2 \%$ and $\sim 8 \%$ when, in reality, this gap is flanked on both sides by intraspecific distances. Note that the total number of specimen-to-specimen comparisons ( $y$-axis) is not comparable with the number of interspecific or intraspecific comparisons conveyed in the text; $(B)$ the number of groups (i.e. species) within the partitions (initial and recursive) as a function of the prior limit between intraspecific variation and interspecific divergence. Note that the dataset included 137 unique taxonomic labels and that, to maintain the same amount of groups in the data, the prior intraspecific variation needs to be allowed to vary between $0 \%$ and $9.32 \%$ (see text for further discussion).

Baseodiscus and the remaining Heteronemertean taxa (Figs 2-4; Supplementary Fig. S1) was also recovered by both Thollesson and Norenburg (2003) and Andrade et al. (2012) and this topology is further solidified by the present study, which increases the sampling within Baseodiscus considerably. Interestingly, an unidentified nemertean specimen (denoted Nemertea sp. SK80 in the trees) collected in freshwater (conductivity: $774 \mu \mathrm{S} / \mathrm{cm}$ ), on Campbell Island, off the south coast of New Zealand $\left(52^{\circ} 32^{\prime} 52^{\prime \prime} \mathrm{S}, 169^{\circ} 4^{\prime} 11^{\prime \prime} \mathrm{E}\right)$, nests well within Baseodiscus. To our knowledge, this is the first record of a freshwater putative Baseodiscus species. However, because of the proximity of the windswept collecting site to the ocean, it is possible that salt spray reaches the site (S. McMurtrie, pers. comm.). Further collection of nemertean specimens from this region needs to be carried out in order to secure the species level identity of the specimen.

With the exception of Riseriellus, all genera within Heteronemertea for which more than one specimen was sampled are non-monophyletic. In some cases, this may be a further testament to the difficulty of species level diagnosis within Nemertea but, in others, it is most likely a confirmation of a much needed large-scale genus level revision of the phylum in general, and of Heteronemertea in particular.

\section{Phylogenetic placement of Hubrechtidae}

The validity of the Pilidiophora clade is reinforced by several autapomorphic morphological and behavioural features, including the pilidium larva (Cantell 1969; Norenburg 1993; Maslakova 2010) and the sharing of similar protonephridial structures (Bürger 1895; but see also Bartolomaeus and von Döhren 2010). A recent study also suggests a relationship between Hubrechtella and Baseodiscus (Heteronemertea) based on their shared subendothelial diagonal muscles in the proboscis and the absence of outer diagonal musculature (Chernyshev et al. 2013), but this would optimise as a plesiomorphy for Heteronemertea under the current scheme, where Valenciniidae constitutes the sister group of all the remaining heteronemerteans. In terms of molecules, however, despite our increased taxon sampling for Hubrechtidae including Hubrechtella dubia, Hubrechtella ijimai (Takakura, 1922) and a Panamanian hubrechtid specimen with unknown specific identity - the phylogenetic placement of the family differs depending on the dataset used. Whereas Hubrechtidae is the sister group of Hoplonemertea in both the ML and MP analyses when employing the full dataset (with negligible support, LBS: 65; PBS: $<50$ ), the family is sister group to Heteronemertea when length-variable regions of $18 \mathrm{~S}$ rRNA and 28S rRNA are excluded, regardless of optimality criterion (LBS: 88; PBS: <50). As such, the Pilidiophora hypothesis (Heteronemertea + Hubrechtidae) is upheld only when excluding these hypervariable regions. This contradicts the finding by Andrade et al. (2012), in which the placement of Hubrechtella dubia was sensitive to optimality criterion but not to the amount and type of data included. It is likely that their hypervariable nature make these regions prone to misalignment, which could affect the placement of these taxa in the phylogeny, although the importance of using such regions has been highlighted in other empirical cases (e.g. Lindgren and Daly 2007; Giribet and Edgecombe 2013). We also employed alignments that used the L-INS-i strategy for all loci, and performed partitioned and unpartitioned ML analyses, as well as a MP analysis for these and the resulting topology (not shown) was always equivalent, indicating that putative misalignments may be difficult to overcome and this question may need to be re-examined with other datasets. Insofar as two recent large-scale phylogenetic analyses of Nemertea included either 28S rRNA (Thollesson and 


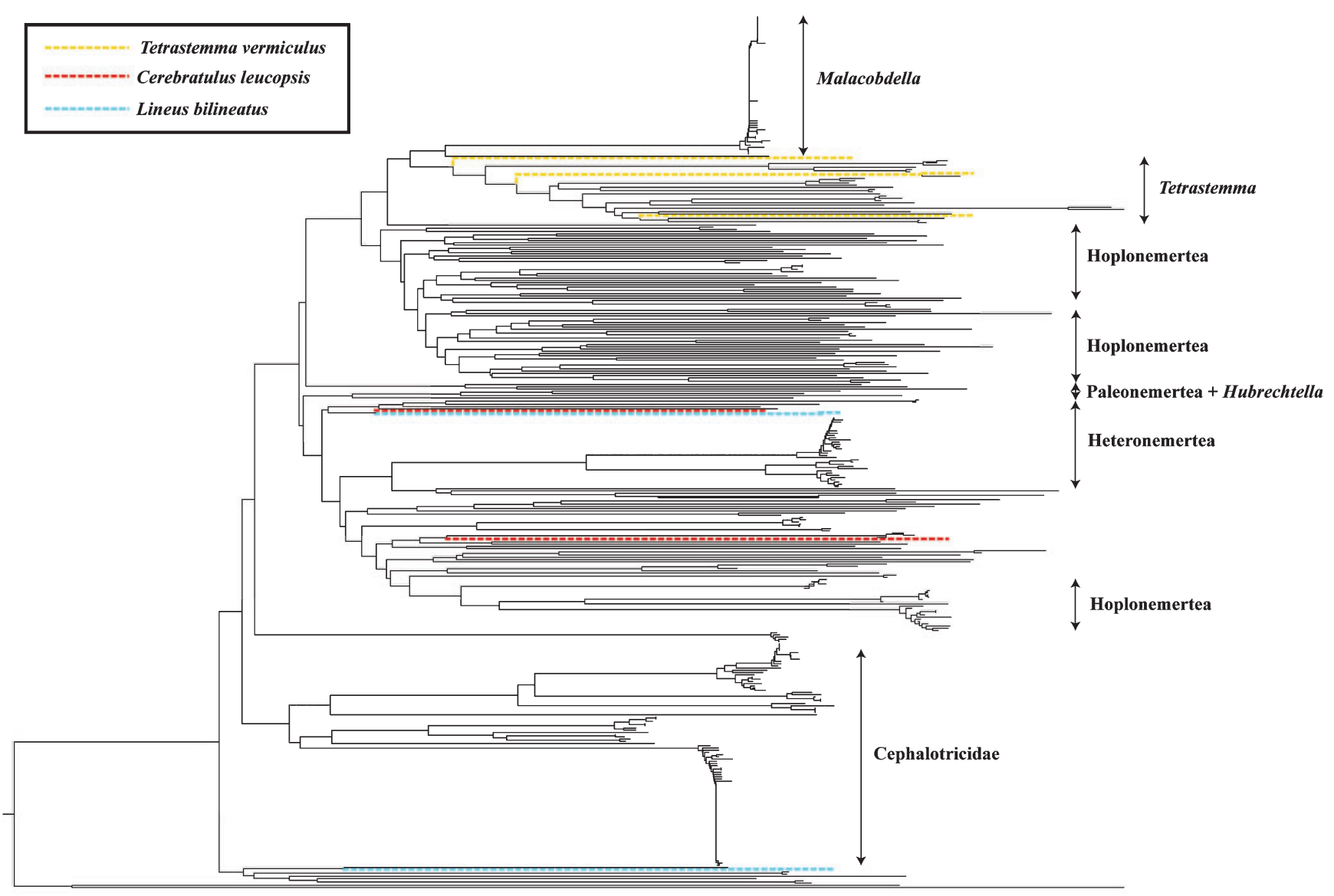

$\overline{0.03 \text { substitutions/site }}$

Fig. 9. Neighbour-joining tree derived from the full COI dataset $(n=394)$, with taxonomic affiliations denoted for some major clusters. Light blue terminal branches lead to specimens of Lineus bilineatus, red lines lead to specimens of Cerebratulus leucopsis, and yellow lines lead to specimens of Tetrastemma vermiculus, which are all further discussed in the text.

Norenburg 2003) or 18 S rRNA (Sundberg et al. 2001) and only one of them (Thollesson and Norenburg, op. cit.) recovers Pilidiophora as monophyletic, we were impelled to evaluate the separate relative impact of the hypervariable regions of $28 \mathrm{~S}$ and $18 \mathrm{~S}$ rRNAs on the placement of Hubrechtidae. We therefore sequentially excluded either the hypervariable regions of $28 \mathrm{~S}$ or $18 \mathrm{~S}$ rRNA and re-ran the ML analysis with the best scoring partitioning scheme, as suggested by PartitionFinder, and using the same settings as mentioned in 'Materials and methods'. The resulting trees (not shown) indicate that the hypervariable regions of both $18 \mathrm{~S}$ rRNA and $28 \mathrm{~S}$ rRNA influence the placement of Hubrechtidae as sister group to Hoplonemertea, as analyses of both datasets recover this relationship.

Interestingly, both statistical tests (SH and $\mathrm{AU}$ ), used here for evaluating ML tree differences, unequivocally agree ( $P=0.00$ for the SH test, $P=3 \mathrm{E}^{-64}$ for the AU test) that the unconstrained tree is significantly different from the tree forced to show monophyly of Pilidiophora. These results indicate that the unconstrained ML analysis (Fig. 3) accurately recovered hubrechtid relationships supported by the six-marker dataset, and that forcing the monophyly of Pilidiophora produces a tree with largely suboptimal likelihood scores. By contrast, in the constrained parsimony analysis, only eight additional steps $(\sim 0.02 \%$ of full tree length) were needed to infer the monophyletic status of Pilidiophora. Although the parsimony scheme used here does not test for statistical significance of the result, it serves as an initial control that, under parsimony, the Pilidiophora hypothesis seems to be only slightly suboptimal compared with the hypothesis presented in Fig. 4.

Given the sensitivity of the placement of Hubrechtidae to different treatments of the available rRNA data, and the meagre support for their placement in all treatments, it is clear that new datasets will be needed to cement the position of this problematic taxon. To this end, large-scale phylogenomic analysis is a promising approach and may also prove useful in solidifying the phyletic status and placement of several other problematic groups, e.g. Palaeonemertea, Micrura and Tetrastemma (Sundberg and Hylbom 1994; Sundberg and Saur 1998; Strand and Sundberg 2005a, 2005b; Strand et al. 2013).

\section{Plectonemertidae and the terrestrial nemerteans}

There has been some contention regarding the natural groupings of terrestrial and freshwater nemerteans (for summaries see 
Mateos and Giribet 2008; Sundberg and Gibson 2008). Presently, there is consensus that, although all higher nemertean taxa have a marine origin, different groups have transitioned from marine to freshwater environments through different modes and on several separate occasions, some via terrestrial habitats and others through purely aquatic habitats (Moore and Gibson 1985; Sundberg 1989a, 1989b; Moore et al. 2001). Moore and Gibson (1988), in revising the classification of terrestrial nemerteans on the basis of similarity in morphological features, split Geonemertes Semper, 1963 into the modern genera of terrestrial nemerteans, recognising that the characters used to diagnose this artificial genus were, in fact, convergent adaptations to terrestriality. Moore and Gibson (1988) placed the supralittoral genus Acteonemertes Pantin, 1969, and the terrestrial genera Argonemertes Moore \& Gibson, 1981 and Antiponemertes Moore \& Gibson, 1981, as well as the freshwater genera Campbellonemertes Moore \& Gibson, 1972 and Potamonemertes Moore \& Gibson, 1973 in the family Plectonemertidae. Plectonemertidae had, until then, been a monotypic family (the marine Plectonemertes Gibson, 1990 being the only genus; note that Gibson's (1990) contribution was in press when Moore and Gibson (1988) was published). Moore and Gibson (1988) also placed the terrestrial genera Katechonemertes Moore \& Gibson, 1981 and Leptonemertes Girard, 1893 within Plectonemertidae but noted that the geographic isolation and non-specialisation of these genera made their inclusion in the family questionable. Later, the results of Crandall's (2001) phylogenetic analysis based on morphology suggested that (i) Plectonemertidae sensu Moore and Gibson 1988 formed a paraphyletic assemblage and indeed should be regarded as a monotypic family (i.e. Plectonemertes did not group with any of the suggested plectonemertid genera), (ii) Acteonemertes, Argonemertes, Antiponemertes, Leptonemertes and Katechonemertes formed a distinct family (later named Acteonemertidae; Chernyshev 2005) and (iii) Campbellonemertes and Potamonemertes either formed a distinct family or two monotypic families. Unfortunately no phylogenetic study attempted to re-evaluate these results, and the taxonomy of the terrestrial nemerteans has remained largely untouched, and consisting of several often monotypic families (see, for example, Mateos and Giribet 2008). To date, molecular sampling of these genera has remained insufficient to provide an independent test of these ideas.

The expanded hoplonemertean phylogenetic hypothesis presented here (Fig. 6 and Supplementary Fig. S2) included Argonemertes australiensis from Tasmania, several taxa labelled as 'Acteonemertidae sp.' by Mateos and Giribet (2008) from the Iberian Peninsula, as well as cf. Potamonemertes percivali from New Zealand, several undescribed plectonemertid species from Australia, Leptonemertes cf. chalicophora from the Iberian Peninsula and Antiponemertes novazealandiae (sequence obtained from Strand and Sundberg 2005b). Both likelihood and parsimony trees show these taxa to form a monophyletic group (LBS: 97; PBS: 56), suggesting the inclusion of (at least) Argonemertes, Leptonemertes, Antiponemertes and Potamonemertes within Plectonemertidae. Contraindicating the proposed exclusion of Potamonemertes from Acteonemertidae by Chernyshev (2005), and the exclusion of Acteonemertidae sensu Chernyshev (2005) from Plectonemertidae by Crandall (2001), in our analysis, these taxa form a monophyletic family (Plectonemertidae sensu Moore and Gibson 1988) with high nodal support. We also sampled four undescribed freshwater Australian species, which we show fall within Plectonemertidae in a strongly supported clade with a New Zealand specimen provisionally identified as Potamonemertes percivali, and whose collection sites provide further insight into the remarkable habitat diversity of this clade. IZ-25173 and IZ-25174 (sp. A; see Figs 3-6), as well as IZ-25175 (sp. B) are unpigmented, eyeless species found in groundwaterfed surface waters, in these respects similar to Potamonemertes, whereas IZ-25169 (sp. C), and IZ-25166 and IZ-25167 (sp. D) were recovered from boreholes used to sample subsurface calcrete aquifers in the arid Pilbara region of Western Australia; Nemertea thus joins the extremely diverse assemblage of stygofauna known from such habitats (Humphreys 2008; Guzik et al. 2011). Groundwater-associated fauna are well known for their poor dispersal ability and, given the wide geographic range (Western Australia, Victoria and New Zealand) of this clade within Australasia, the existence of this clade may be evidence for a large and possibly geologically old radiation of stygofaunal nemerteans, as has been demonstrated for several other taxa (e.g. phreatoicidean isopods; Wilson 2008). Further sampling of groundwater-associated nemerteans (a methodologically challenging prospect, given the need to observe living specimens and fix appropriately for histological study) within Australia, New Zealand, and possibly other former Gondwanan continental fragments, will be necessary to test this idea. In any case, the existence of this clade is consistent with the notion of a much larger diversity of continental Plectonemertidae than has perhaps been fully appreciated to date (Mateos and Giribet 2008). Judging from the partially fragmented dataset used here (e.g. only $18 \mathrm{~S}$ rRNA was available for Antiponemertes novazealandiae), it would be premature to synonymise Acteonemertidae and Potamonemertes with Plectonemertidae, especially in the absence of sequence data from Plectonemertes and Acteonemertes, but the recovery of this clade by the present study represents yet another line of evidence in support of Plectonemertidae sensu Moore and Gibson (1988). Pending inclusion of marine taxa such as Acteonemertes and Plectonemertes it is difficult to comment on the specific macroevolutionary routes by which plectonemertid taxa have come to flourish in freshwater and terrestrial habitats (Moore and Gibson 1985, 1988). A fuller taxon sampling should illuminate relationships within this enigmatic nemertean family and hence the specific sequence of habitat colonisation.

The other clade of terrestrial nemerteans includes Geonemertes pelaensis Semper, 1863, which appears related to Malacobdella and not to Prosorhochmus Keferstein, 1862, with whom it was once grouped in the family Prosorhochmidae. Geonemertes thus appears nested in a clade that includes a diversity of monostiliferan genera with interesting reproductive or life-strategy behaviours, like the parasitic and commensal genera Malacobdella, Gononemertes Bergendal, 1900 and Vieitezia Junoy, Andrade \& Giribet, 2011 (see discussion in Junoy et al. 2011), cocoon-forming species (Taboada et al. 2013), plus other free-living forms including Tetranemertes Chernyshev, 1992, Oerstedia Quatrefages, 1846, 
Prosorhochmus and Tetrastemma. This clade is well supported (LBS: 97) and appears as sister group to Plectonemertidae (LBS: 98).

\section{DNA barcoding gap}

DNA barcoding is a promising tool for specimen identification (e.g. Fernández-Álvarez and Machordom 2013), especially for organisms that are relatively difficult to identify, such as nemerteans. Indeed, recent nemertean species descriptions are associated with COI barcodes (Strand and Sundberg 2011; Strand et al. 2013; see also Junoy et al. 2011; Kajihara et al. 2011; Taboada et al. 2013). However, among other factors, the functionality of DNA barcoding is contingent on two presumptions: the presence of a high-coverage barcode database, and the presence, within any given group of organisms, of a wide DNA barcoding gap - the difference between the highest intraspecific variation and the lowest interspecific divergence (for discussion, see Tautz et al. 2002, 2003; Lipscomb et al. 2003; Moritz and Cicero 2004; Will and Rubinoff 2004; Schander and Willassen 2005; Ebach and Holdredge 2005; DeSalle et al. 2005; Rubinoff et al. 2006; Kvist 2013). At first glance, our average intraspecific and interspecific variation values suggest the presence of a wide barcoding gap (intraspecific: $1.14 \% \pm 2.87$; interspecific: $19.59 \% \pm 3.55$; Fig. 7), but a closer investigation of the overall values presents a more dubious scenario. Inasmuch as the lowest interspecific divergence values $(<1 \%)$ occur between either synonymous taxa (e.g. Myoisophagus sanguineus and Ramphogordius sanguineus (Rathke, 1799); Riser 1994; Kajihara et al. 2008) or between somewhat cryptic taxa (e.g. Prosorhochmus claperedii Keferstein, 1862, Prosorhochmus americanus Gibson, Moore, Ruppert \& Turbeville, 1986 and Prosorhochmus chafarinensis Frutos, Montalvo \& Junoy, 1998), the low interspecific values may merely illustrate the difficulty of species level identifications of some taxa. This difficulty is indeed reflected in the implausibly high intraspecific variation present between some specimens with identical taxonomic labels (e.g. $20.87 \%$ within Cerebratulus leucopsis, $19.01 \%$ within Lineus bilineatus, and $17.38 \%$ within Tetrastemma vermiculus). As mentioned above, most (88\%) of the intraspecific comparisons resulted in distance values below $2 \%$, a figure that has become somewhat standard in barcoding practice for conspecific variation (Smith et al. 2005; but see Boyer et al. 2007 for a counter example), and it is possible that the remaining $12 \%$ are represented by wrongly labelled taxa. As such, any user of GenBank COI sequences pertaining to the aforementioned taxa (and surely numerous other sequences) should indeed be cautious of the inferred taxonomic labels. In this regard, DNA barcoding holds particular promise, as it may allow for more unambiguous and objective identification, free of homoplastic characters or convergent evolution (although a rigorous database of authoritative sequences need first be created, as mentioned above). Regardless of this, however, it is difficult to set an arbitrary cut-off limit on interspecific versus intraspecific variation for the inclusion or exclusion of a specimen in a species complex, especially as the values recovered by the present study are present as a somewhat continuous range (see Supplementary Tables 1 and 2).
The unreasonably high intraspecific distance values are further underscored by ABGD. Species diversity estimation by ABGD (Fig. $8 B$ ) shows that, to maintain the species diversity indicated by the taxonomic labels (137 unique taxonomic labels, i.e. putative species), the prior intraspecific distance needs to be allowed to vary between $0.00 \%$ and $9.32 \%$, an upper limit that is much higher than normal estimations of intraspecific variation (e.g. Hebert et al. 2003a, 2003b; Smith et al. 2005; Ratnasingham and Hebert 2007). Importantly, ABGD calculates all pairwise distances without considering species affinities and uses an a priori determined range of intraspecific distances to infer a model-based confidence limit for the empirical divergences. As a result, relatively high intraspecific variation values can easily be confused with low interspecific divergence values, making the resulting distribution of values difficult to interpret. That is, correct interpretation of the results from $A B G D$ presupposes a reasonable range of intraspecific and interspecific divergences. This is clearly not the case within Nemertea, likely due to the aforementioned problems of specimen identification, such that Fig. $8 \mathrm{~A}$ indicates the presence of a barcoding gap between $\sim 2 \%$ and $\sim 8 \%$ divergence. Unbeknownst to any investigator operating without knowledge of the taxonomic labels associated with the sequences, this gap is flanked on both sides by intraspecific distance values. Strictly speaking, the putative 'barcoding gap' of this dataset occurs in the centre of the distribution of intraspecific values, as opposed to its normal occurrence between intraspecific variation and interspecific divergence. The neighbour-joining tree, constructed from the uncorrected $p$-distances of the COI sequences (Fig. 9), corroborates this finding. The general topology of the tree implies that branches between conspecifics are much shorter than those between nonconspecifics, notwithstanding the several taxa with identical taxonomic labels, which are recovered in very disparate parts of the tree (see branch colours in Fig. 9 for three examples).

Taking into account the full body of results presented here, it seems reasonable to suggest that DNA barcoding may work for Nemertea, insofar as a distinctly wide barcoding gap may exist, pending higher accuracy in species level identifications (authoritative barcodes sensu Kvist et al. 2010; see Strand and Sundberg 2011) of the specimens that will provide the backbone of the barcode database.

\section{Acknowledgements}

This work was supported by funding from the Wenner-Gren Foundations, Helge Ax:son Johnson's Foundation, Sixten Gemzeus' Foundation and Olle Engkvist Byggmästare's Foundation to S.K., with fieldwork support by an NSF EAPSI award to C.E.L., as well as by internal funds from the Museum of Comparative Zoology to G.G. The Harvard FAS Center for Systems Biology provided sequencing support, and Erin McIntyre and Sónia Andrade provided DNA sequences and much appreciated technical support. Collecting and permitting for the Cabrera National Park samples was facilitated by Pep Amengual and Enrique Alonso; Alfonso HerreraBachiller and Miguel Candelas provided good company and their nemertean expertise. We particularly thank the following colleagues for aid in collecting specimens: A. Herrera (various tetrastemmatids, Notospermus geniculatus and Oerstedia spp.), J. L. Norenburg (cf. Ototyphlonemertes pallida), M. L. Schwartz (Micrura verrilli and Amphiporus formidabilis), R. Mesibov (Argonemertes australiensis), H. Kajihara (Carinoma hamanako and Hubrechtella ijimai), R. Leijs and R. King (various 
plectonemertids), J. T. Cannon and K. M. Kocot (Malacobdella), N. C. Boustead and D. P. Gray (cf. Potamonemertes percivali). The putative Baseodiscus specimen (SK80) and associated information was provided by EOS Ecology and was collected during the 2010-11 Campbell Island Biocentennial Expedition (CIBE). We also thank the Willi Hennig Society for making TNT freely available. Two anonymous reviewers and editor Nerida Wilson provided comments that helped improve this article.

\section{References}

Andrade, S. C. S., Strand, M., Schwartz, M., Chen, H., Kajihara, H., von Döhren, J., Sun, S., Junoy, J., Thiel, M., Norenburg, J. L., Turbeville, J. M., Giribet, G., and Sundberg, P. (2012). Disentangling ribbon worm relationships: multi-locus analysis supports traditional classification of the phylum Nemertea. Cladistics 28, 141-159. doi:10.1111/j.10960031.2011.00376.x

Appeltans, W., Ahyong, S. T., Anderson, G., Angel, M. V., Artois, T., Bailly, N., Bamber, R., Barber, A., Bartsch, I., Berta, A., Blazewicz-Paszkowycz, M., Bock, P., Boxshall, G., Boyko, C. B., Brandao, S. N., Bray, R. A., Bruce, N. L., Cairns, S. D., Chan, T. Y., Cheng, L., Collins, A. G., Cribb, T., Curini-Galletti, M., Dahdouh-Guebas, F., Davie, P. J., Dawson, M. N., De Clerck, O., Decock, W., De Grave, S., de Voogd, N. J., Domning, D. P., Emig, C. C., Erséus, C., Eschmeyer, W., Fauchald, K., Fautin, D. G., Feist, S. W., Fransen, C. H., Furuya, H., Garcia-Alvarez, O., Gerken, S., Gibson, D., Gittenberger, A., Gofas, S., Gomez-Daglio, L., Gordon, D. P., Guiry, M. D., Hernandez, F., Hoeksema, B. W., Hopcroft, R. R., Jaume, D., Kirk, P., Koedam, N., Koenemann, S., Kolb, J. B., Kristensen, R. M., Kroh, A., Lambert, G., Lazarus, D. B., Lemaitre, R., Longshaw, M., Lowry, J., Macpherson, E., Madin, L. P., Mah, C., Mapstone, G., McLaughlin, P. A., Mees, J., Meland, K., Messing, C. G., Mills, C. E., Molodtsova, T. N., Mooi, R., Neuhaus, B., Ng, P. K., Nielsen, C., Norenburg, J., Opresko, D. M., Osawa, M., Paulay, G., Perrin, W., Pilger, J. F., Poore, G. C., Pugh, P., Read, G. B., Reimer, J. D., Rius, M., Rocha, R. M., Saiz-Salinas, J. I., Scarabino, V., Schierwater, B., Schmidt-Rhaesa, A., Schnabel, K. E., Schotte, M., Schuchert, P., Schwabe, E., Segers, H., Self-Sullivan, C., Shenkar, N., Siegel, V., Sterrer, W., Stöhr, S., Swalla, B., Tasker, M. L., Thuesen, E. V., Timm, T., Todaro, M. A., Turon, X., Tyler, S., Uetz, P., van der Land, J., Vanhoorne, B., van Ofwegen, L. P., van Soest, R. W. M., Vanaverbeke, J., Walker-Smith, G., Walter, T. C., Warren, A., Williams, G. C., Wilson, S. P., and Costello, M. J. (2012). The magnitude of global marine species diversity. Current Biology 22, 2189-2202. doi:10.1016/ j.cub.2012.09.036

Bartolomaeus, T., and von Döhren, J. (2010). Comparative morphology and evolution of the nephridia in Nemertea. Journal of Natural History 44, 2255-2286. doi:10.1080/00222933.2010.503941

Bell, P. J., and Hickman, J. L. (1985). Observations on Carcinonemertes (Nemertea: Carcinonemertidae) associated with the smooth pebble crab, Philyra laevis. Papers and Proceedings of the Royal Society of Tasmania 119, 65-68.

Berg, G. (1985). Annulonemertes gen. nov., a new segmented hoplonemertean. In 'The Origins and Relationships of Lower Invertebrates'. (Eds S. Conway Morris, J. D. George, R. Gibson and H. Platt.) pp. 200-209. (Clarendon Press, UK.)

Boyer, S. L., Baker, J. M., and Giribet, G. (2007). Deep genetic divergences in Aoraki denticulata (Arachnida, Opiliones, Cyphophthalmi): a widespread 'mite harvestman' defies DNA taxonomy. Molecular Ecology 16, 4999-5016. doi:10.1111/j.1365-294X.2007.03555.x

Bürger, O. (1895). Die Nemertinen des Golfes von Neapel und der angrenzenden Meeres-Abschnitte. Fauna und Flora des Golfes von Neapel 22, 1-743.

Cantell, C.-E. (1969). Morphology, development, and biology of the pilidium larvae (Nemertini) from the Swedish west coast. Zoologiska Bidrag från Uppsala 38, 61-111.
Caplins, S., Penna-Diaz, M. A., Godoy, E., Valdivia, N., Turbeville, J. M., and Thiel, M. (2012). Activity patterns and predatory behaviour of an intertidal nemertean from rocky shores: Prosorhochmus nelsoni (Hoplonemertea) from the Southeast Pacific. Marine Biology 159, 1363-1374. doi:10.1007/s00227-012-1916-7

Castresana, J. (2000). Selection of conserved blocks from multiple alignments for their use in phylogenetic analysis. Molecular Biology and Evolution 17, 540-552. doi:10.1093/oxfordjournals.molbev.a026334

Chen, H., Strand, M., Norenburg, J. L., Sun, S., Kajihara, H., Chernyshev, A. V., Maslakova, S. A., and Sundberg, P. (2010). Statistical parsimony networks and species assemblages in cephalothricid nemerteans (Nemertea). PLoS ONE 5, e12885. doi:10.1371/journal.pone.0012885

Chernyshev, A. V. (2003). Classification system for the higher taxa of enoplan nemerteans (Nemertea: Enopla). Russian Journal of Marine Biology 29, S57-S65. doi:10.1023/B:RUMB.0000011717.06390.30

Chernyshev, A. V. (2005). System of families of enoplan nemerteans of the order Eumonostilifera (Nemertea: Enopla). Russian Journal of Marine Biology 31, S27-S33. doi:10.1007/s11179-006-0012-6

Chernyshev, A. V., Magarlamov, T. Y., and Turbeville, J. M. (2013). Morphology of the proboscis of Hubrechtella juliae (Nemertea, Pilidiophora): implications for pilidiophoran monophyly. Journal of Morphology 274, 1397-1414. doi:10.1002/jmor.20189

Colgan, D. J., McLauchlan, A., Wilson, G. D. F., Livingston, S. P., Edgecombe, G. D., Macaranas, J., Cassis, G., and Gray, M. R. (1998). Histone $\mathrm{H} 3$ and U2 snRNA DNA sequences and arthropod molecular evolution. Australian Journal of Zoology 46, 419-437. doi:10.1071/ ZO98048

Crandall, F. B. (2001). A cladistics view of the Monostilifera (Hoplonemertea) with interwoven rhynchocoel musculature: a preliminary assessment. Hydrobiologia 456, 87-110. doi:10.1023/A:1013031900458

DeSalle, R., Egan, M. G., and Siddall, M. (2005). The unholy trinity: taxonomy, species delimitation and DNA barcoding. Philosophical Transactions of the Royal Society of London. Series B, Biological Sciences 360, 1905-1916. doi:10.1098/rstb.2005.1722

Dunn, C. W., Hejnol, A., Matus, D. Q., Pang, K., Browne, W. E., Smith, S. A., Seaver, E. C., Rouse, G. W., Obst, M., Edgecombe, G. D., Sørensen, M. V., Haddock, S. H. D., Schmidt-Rhaesa, A., Okusu, A., Kristensen, R. M., Wheeler, W. C., Martindale, M. Q., and Giribet, G. (2008). Broad taxon sampling improves resolution of the Animal Tree of Life. Nature 452, 745-749. doi:10.1038/nature06614

Ebach, M. C., and Holdredge, C. (2005). DNA barcoding is no substitute for taxonomy. Nature 434, 697. doi:10.1038/434697b

Edgecombe, G. D., and Giribet, G. (2006). A century later - a total evidence re-evaluation of the phylogeny of scutigeromorph centipedes (Myriapoda: Chilopoda). Invertebrate Systematics 20, 503-525. doi:10.1071/IS05044

Fernández-Álvarez, F. Á., and Machordom, A. (2013). DNA barcoding reveals a cryptic nemertean invasion in Atlantic and Mediterranean waters. Helgoland Marine Research 67, 599-605. doi:10.1007/s10152013-0346-3

Folmer, O., Black, M., Hoeh, W., Lutz, R., and Vrijenhoek, R. C. (1994). DNA primers for amplification of mitochondrial cytochrome $c$ oxidase subunit I from diverse metazoan invertebrates. Molecular Marine Biology and Biotechnology 3, 294-299.

Gibson, R. (1967). Occurrence of the entocommensal rhynchocoelan, Malacobdella grossa, in the oval piddock, Zirfaea crispata, on the Yorkshire coast. Journal of the Marine Biological Association of the United Kingdom 47, 301-317. doi:10.1017/S0025315400056411

Gibson, R. (1985). The need for a standard approach to taxonomic descriptions of Nemertea. American Zoologist 25, 5-14.

Gibson, R. (1990). The macrobenthic nemertean fauna of Hong Kong. In 'Proceedings of the Second International Marine Biological Workshop: the Marine Flora and Fauna of Hong Kong and Southern China 1'. (Ed. B. S. Morton.) (University Press: Hong Kong.) 
Gibson, R. (1995). Nemertean genera and species of the world: an annotated checklist of original names and description citations, synonyms, current taxonomic status, habitats and recorded zoogeographic distribution. Journal of Natural History 29, 271-561. doi:10.1080/00222939500 770161

Giribet, G., and Edgecombe, G. D. (2013). Stable phylogenetic patterns in scutigeromorph centipedes (Myriapoda: Chilopoda: Scutigeromorpha): dating the diversification of an ancient lineage of terrestrial arthropods. Invertebrate Systematics 27, 485-501. doi:10.1071/IS13019

Giribet, G., Carranza, S., Baguñá, J., Riutort, M., and Ribera, C. (1996). First molecular evidence for the existence of a Tardigrada + Arthropoda clade. Molecular Biology and Evolution 13, 76-84. doi:10.1093/oxfordjournals. molbev.a025573

Giribet, G., Dunn, C. W., Edgecombe, G. D., Hejnol, A., Martindale, M. Q., and Rouse, G. W. (2009). Assembling the spiralian tree of life. In 'Animal Evolution: Genomes, Fossils and Trees'. (Eds M. J. Telford and D. T. J. Littlewood.) pp. 52-64. (Oxford University Press: Oxford, UK.)

Giribet, G., Vogt, L., Pérez González, A., Sharma, P., and Kury, A. B. (2010). A multilocus approach to harvestman (Arachnida: Opiliones) phylogeny with emphasis on biogeography and the systematics of Laniatores. Cladistics 26, 408-437.

Goloboff, P. A., Farris, J. S., and Nixon, K. C. (2008). TNT, a free program for phylogenetic analysis. Cladistics 24, 774-786. doi:10.1111/j.10960031.2008.00217.x

Guzik, M. T., Austain, A. D., Cooper, S. J., Harvey, M. S., Humphreys, W. F., Bradford, T., Eberhard, S. M., King, R. A., Leys, R., Muirhead, K. A., and Tomlinson, M. (2011). Is the Australian fauna uniquely diverse? Invertebrate Systematics 24, 407-418. doi:10.1071/IS10038

Härlin, M. S., and Sundberg, P. (1995). Cladistic analysis of the eureptantic nemerteans (Nemertea: Hoplonemertea). Invertebrate Taxonomy 9, 1211-1229. doi:10.1071/IT9951211

Hebert, P. D. N., Cywinska, A., Ball, S. L., and deWaard, J. R. (2003a). Biological identifications through DNA barcodes. Proceedings of the Royal Society of London. Series B, Biological Sciences 270, 313-321. doi: $10.1098 / \mathrm{rspb} .2002 .2218$

Hebert, P. D. N., Ratnasingham, S., and deWaard, J. R. (2003b). Barcoding animal life: cytochrome $c$ oxidase subunit 1 divergences among closely related species. Proceedings of the Royal Society of London B: Biological Sciences 270, S96-S99.

Hejnol, A., Obst, M., Stamatakis, A., Ott, M., Rouse, G. W., Edgecombe, G. D., Martinez, P., Baguña, J., Bailly, X., Jondelius, U., Wiens, M., Müller, W. E. G., Seaver, E., Wheeler, W. C., Martindale, M. Q., Giribet, G., and Dunn, C. W. (2009). Assessing the root of bilaterian animals with scalable phylogenomic methods. Proceedings of the Royal Society of London. Series B, Biological Sciences 276, 4261-4270. doi:10.1098/ rspb.2009.0896

Humphreys, W. F. (2008). Rising from Down Under: developments in subterranean biodiversity in Australia from a groundwater fauna perspective. Invertebrate Systematics 22, 85-101. doi:10.1071/IS07016

Junoy, J., Andrade, S. C. S., and Giribet, G. (2011). Phylogenetic placement of a new hoplonemertean species commensal of ascidians. Invertebrate Systematics 24, 616-629. doi:10.1071/IS10036

Kajihara, H., Gibson, R., and Mawatari, S. F. (2000). Redescription and taxonomic reassessment of Nemertellina minuta Friedrich, 1935 sensu Yamoaka, 1940 (Nemertea, Hoplonemertea, Monostilifera). Zoological Science 17, 265-276. doi:10.2108/zsj.17.265

Kajihara, H., Chernyshev, A. V., Sun, S.-C., Sundberg, P., and Crandall, F. B. (2008). Checklist of nemertean genera and species published between 1995 and 2007. Species Diversity 13, 245-274.

Kajihara, H., Yamasaki, H., and Andrade, S. C. S. (2011). Carinoma hamanako sp. nov. (Nemertea: Palaeonemertea), the first representative of the genus from the Northwest Pacific. Species Diversity 16, 149-165.
Katoh, K., and Standley, D. M. (2013). MAFFT multiple sequence alignment software version 7: improvements in performance and usability. Molecular Biology and Evolution 30, 772-780. doi:10.1093/ molbev/mst010

Kocot, K. M., Cannon, J. T., Todt, C., Citarella, M. R., Kohn, A. B., Meyer, A., Santos, S. R., Schander, C., Moroz, L. L., Lieb, B., and Halanych, K. M. (2011). Phylogenomics reveals deep molluscan relationships. Nature 477, 452-456. doi:10.1038/nature 10382

Kvist, S. (2013). Barcoding in the dark?: a critical view of the sufficiency of zoological DNA barcoding databases and a plea for broader integration of taxonomic knowledge. Molecular Phylogenetics and Evolution 69, 39-45. doi:10.1016/j.ympev.2013.05.012

Kvist, S., Oceguera-Figueroa, A., Siddall, M. E., and Erséus, C. (2010). Barcoding, types and the Hirudo files: using information content to critically evaluate the identity of DNA barcodes. Mitochondrial DNA 21, 198-205. doi:10.3109/19401736.2010.529905

Lanfear, R., Calcott, B., Ho, S. Y. W., and Guindon, S. (2012). PartitionFinder: combined selection of partitioning schemes and substitution models for phylogenetic analyses. Molecular Biology and Evolution 29, 1695-1701. doi:10.1093/molbev/mss020

Lindgren, A. R., and Daly, M. (2007). The impact of length-variable data and alignment criterion on the phylogeny of Decapodiformes (Mollusca: Cephalopoda). Cladistics 23, 464-476. doi:10.1111/j.10960031.2007 .

00160.x

Lipscomb, D., Platnick, N., and Wheeler, Q. (2003). The intellectual content of taxonomy: a comment on DNA taxonomy. Trends in Ecology \& Evolution 18, 65-66. doi:10.1016/S0169-5347(02)00060-5

Maddison, W. P., and Maddison, D. R. (2010). Mesquite: a modular system for evolutionary analysis version 2.5. Available from http:// mesquiteproject.org. [verified 4 June 2014]

Mahon, A. R., Thornhill, D. J., Norenburg, J. L., and Halanych, K. M. (2010). DNA uncovers Antarctic nemertean biodiversity and exposes a decadesold cold case of asymmetric inventory. Polar Biology 33, 193-202. doi:10.1007/s00300-009-0696-0

Maslakova, S. A. (2010). Development to metamorphosis of the nemertean pilidium larva. Frontiers in Zoology 7, 30. doi:10.1186/ 1742-9994-7-30

Mateos, E., and Giribet, G. (2008). Exploring the molecular diversity of terrestrial nemerteans (Hoplonemertea, Monostilifera, Acteonemertidae) in a continental landmass. Zoologica Scripta 37, 235-243. doi:10.1111/ j.1463-6409.2008.00324.x

McDermott, J. J., and Roe, P. (1985). Food, feeding behavior and feeding ecology of nemerteans. American Zoologist 25, 113-125.

McIntosh, W. C. (1873). 'A Monograph of the British Annelids. Part 1. The Nemerteans.' (Ray Society, London.)

Miller, M. A., Pfeiffer, W., and Schwartz, T. (2010). Creating the CIPRES Science Gateway for inference of large phylogenetic trees. In 'Proceedings of the Gateway Computing Environments Workshop (GCE), New Orleans, LA'. pp. 1-8.

Moore, J., and Gibson, R. (1981). The Geonemertes problem (Nemertea). Journal of Zoology 194, 175-201. doi:10.1111/j.1469-7998.1981. tb05768.x

Moore, J., and Gibson, R. (1985). The evolution and comparative physiology of terrestrial and freshwater nemerteans. Biological Reviews of the Cambridge Philosophical Society 60, 257-312. doi:10.1111/j.1469-185X.1985.tb00716.x

Moore, J., and Gibson, R. (1988). Further studies on the evolution of land and freshwater nemerteans: generic relationships among the paramonostiliferous taxa. Journal of Zoology 216, 1-20. doi:10.1111/ j.1469-7998.1988.tb02410.x

Moore, J., Gibson, R., and Jones, H. D. (2001). Terrestrial nemerteans thirty years on. Hydrobiologia 456, 1-6. doi:10.1023/A:1013052728257 
Moritz, C., and Cicero, C. (2004). DNA barcoding: promise and pitfalls. PLoS Biology 2, e354. doi:10.1371/journal.pbio.0020354

Norenburg, J. L. (1993). Riserius pugetensis gen. n., sp. n. (Nemertina: Anopla), a new mesopsammic species, and comments onphylogenetics of some anoplan characters. Hydrobiologia 266, 203-218. doi:10.1007/ BF00013369

Palumbi, S., Martin, A., Romano, S., McMillan, W. O., Stice, L., and Grabowski, G. (1991). 'The Simple Fools Guide to PCR, ver. 2.0.' (Department of Zoology and Kewalo Marine Laboratory, University of Hawaii: Honolulu, HI.)

Pennak, R. W. (1963). Ecological affinities and origins of free-living acelomate freshwater invertebrates. In 'The Lower Metazoa'. (Eds E. C. Dougherty, Z. N. Brown, E. D. Hanson and W. D. Hartman.) pp. 435-451. (University of California Press: Berkeley, CA.)

Pineau, P., Henry, M., Suspène, R., Marchio, A. S., Dettai, A., Debruyne, R., Petit, T., Lécu, A., Moisson, P., Dejean, A., Wain-Hobson, S., and Vartanian, J. P. (2005). A universal primer set for PCR amplification of nuclear histone $\mathrm{H} 4$ genes from all animal species. Molecular Biology and Evolution 22, 582-588. doi:10.1093/molbev/msi053

Puillandre, N., Lambert, A., Brouillet, S., and Achaz, G. (2012). ABGD, automatic barcode gap discovery for primary species delimitation. Molecular Ecology 21, 1864-1877. doi:10.1111/j.1365-294X.2011. 05239.x

Ratnasingham, S., and Hebert, P. D. N. (2007). BOLD: the Barcode of Life Data System. Available at: http://www.barcodinglife.org. Molecular Ecology Resources 7, 355-364. [Verified 4 June 2014]

Riser, N. W. (1994). The morphology and generic relationships of some fissiparous heteronemertines. Proceedings of the Biological Society of Washington 107, 548-556.

Rogers, A. D., Thorpe, J. P., and Gibson, R. (1995). Genetic evidence for the occurrence of a cryptic species with the littoral nemerteans Lineus ruber and L. viridis (Nemertea: Anopla). Marine Biology 1995, $305-316$.

Rubinoff, D., Cameron, S., and Will, K. (2006). A genomic perspective on the shortcomings of mitochondrial DNA for "barcoding" identification. The Journal of Heredity 97, 581-594. doi:10.1093/jhered/es1036

Schander, C., and Willassen, E. (2005). What can biological barcoding do for marine biology? Marine Biology Research 1, 79-83. doi:10.1080/ 17451000510018962

Schultze, M. S. (1851). 'Beiträge zur Naturgeschichte den Turbellarien.' (C.A. Koch: Greifswald, Germany.)

Schwartz, M. L., and Norenburg, J. L. (2001). Can we infer heteronemertean phylogeny from available morphological data? Hydrobiologia 456, 165-174. doi:10.1023/A:1013093629108

Schwartz, M. L., and Norenburg, J. L. (2005). Three new species of Micrura (Nemertea: Heteronemertea) and a new type of heteronemertean larva from the Caribbean Sea. Caribbean Journal of Science 41, $528-543$.

Schwendinger, P. J., and Giribet, G. (2005). The systematics of the southeast Asian genus Fangensis Rambla (Opiliones: Cyphophthalmi: Stylocellidae). Invertebrate Systematics 19, 297-323. doi:10.1071/ IS05023

Shimodaira, H. (2002). An approximately unbiased test of phylogenetic tree selection. Systematic Biology 51, 492-508. doi:10.1080/10635150 290069913

Shimodaira, H., and Hasegawa, M. (1999). Multiple comparisons of loglikelihoods with applications to phylogenetic inference. Molecular Biology and Evolution 16, 1114-1116. doi:10.1093/oxfordjournals. molbev.a026201

Shimodaira, H., and Hasegawa, M. (2001). CONSEL: for assessing the confidence of phylogenetic tree selection. Bioinformatics 17, 1246-1247. doi:10.1093/bioinformatics/17.12.1246

Smith, M. A., Fisher, B. L., and Hebert, P. D. N. (2005). DNA barcoding for effective biodiversity assessment of a hyperdiverse arthropod group: the ants of Madagascar. Philosophical Transactions of the Royal Society of London. Series B, Biological Sciences 360, 1825-1834. doi:10.1098/ rstb.2005.1714

Stamatakis, A. (2006). RAxML-VI-HPC: maximum likelihood-based phylogenetic analyses with thousands of taxa and mixed models. Bioinformatics 22, 2688-2690. doi:10.1093/bioinformatics/btl446

Stothard, P. (2000). The sequence manipulation suite: JavaScript programs for analyzing and formatting protein and DNA sequences. BioTechniques 28, 1102-1104.

Strand, M., and Sundberg, P. (2005a). Delimiting species in the hoplonemertean genus Tetrastemma (phylum Nemertea): morphology is not concordant with phylogeny as evidenced from mtDNA sequences. Biological Journal of the Linnean Society. Linnean Society of London $\mathbf{8 6}$, 201-212. doi:10.1111/j.1095-8312.2005.00535.x

Strand, M., and Sundberg, P. (2005b). Genus Tetrastemma Ehrenberg, 1831 (phylum Nemertea) - a natural group? Phylogenetic relationships inferred from partial 18SrRNA sequences. Molecular Phylogenetics and Evolution 37, 144-152. doi:10.1016/j.ympev.2005.02.006

Strand, M., and Sundberg, P. (2011). A DNA-based description of a new nemertean (phylum Nemertea) species. Marine Biology Research 7, 63-70. doi:10.1080/17451001003713563

Strand, M., Hererra-Bachiller, A., Nygren, A., and Kånneby, T. (2013). A new nemertean species: what are the useful characters for ribbon worm descriptions? Journal of the Marine Biological Association of the United Kingdom, In press.

Sundberg, P. (1989a). Phylogeny and cladistic classification of the Paramonostiliferous family Plectonemertidae (phylum Nemertea). Cladistics 5, 87-100. doi:10.1111/j.1096-0031.1989.tb00484.x

Sundberg, P. (1989b). Phylogeny and cladistics classification of terrestrial nemerteans: the genera Pantinonemertes Moore \& Gibson and Geonemertes Semper. Zoological Journal of the Linnean Society 95, 363-372. doi:10.1111/j.1096-3642.1989.tb02316.x

Sundberg, P., and Gibson, R. (2008). Global diversity of nemerteans (Nemertea) in freshwater. Hydrobiologia 595, 61-66. doi:10.1007/ s10750-007-9004-6

Sundberg, P., and Hylbom, R. (1994). Phylogeny of the nemertean subclass Palaeonemertea (Anopla, Nemertea). Cladistics 10, 347-402. doi:10.1111/j.1096-0031.1994.tb00185.x

Sundberg, P., and Saur, M. (1998). Molecular phylogeny of some European heteronemertea (Nemertea) species and the monophyletic status of Riseriellus, Lineus, and Micrura. Molecular Phylogenetics and Evolution 10, 271-280. doi:10.1006/mpev.1998.0543

Sundberg, P., and Strand, M. (2007). Annulonemertes (phylum Nemertea): when segments do not count. Biology Letters 3, 570-573. doi:10.1098/ rsbl.2007.0306

Sundberg, P., and Svensson, M. (1994). Homoplasy, character function, and nemertean systematics. Journal of Zoology 234, 253-263. doi:10.1111/ j.1469-7998.1994.tb06073.x

Sundberg, P., Turbeville, J. M., and Lindh, S. (2001). Phylogenetic relationships among higher nemertean (Nemertea) taxa inferred from $18 \mathrm{~S}$ rRNA sequences. Molecular Phylogenetics and Evolution 20, 327-334. doi:10.1006/mpev.2001.0982

Sundberg, P., Thuroczy Vodoti, E., and Strand, M. (2010). DNA barcoding should accompany taxonomy - the case of Cerebratulus spp. (Nemertea). Molecular Ecology Resources 10, 274-281. doi:10.1111/j.1755-0998. 2009.02774.x

Taboada, S., Junoy, J., Andrade, S. C. S., Giribet, G., Cristobo, J., and Avila, C. (2013). On the identity of two Antarctic brooding nemerteans: redescription of Antarctonemertes valida (Bürger, 1893) and description of a new species in the genus Antarctonemertes Friedrich, 1955 (Nemertea, Hoplonemertea). Polar Biology 36, 1415-1430. doi:10.1007/s00300-013-1360-2

Tamura, K., Peterson, D., Peterson, N., Stecher, G., Nei, M., and Kumar, S. (2011). MEGA5: molecular evolutionary genetics analysis using 
maximum likelihood, evolutionary distance, and maximum parsimony methods. Molecular Biology and Evolution 28, 2731-2739. doi:10.1093/ molbev/msr121

Tautz, D., Arctander, P., Minelli, A., Thomas, R. H., and Vogler, A. P. (2002). DNA points the way ahead in taxonomy. Nature 418, 479. doi:10.1038/ 418479a

Tautz, D., Arctander, P., Minelli, A., Thomas, R. H., and Vogler, A. P. (2003). A plea for DNA taxonomy. Trends in Ecology \& Evolution 18, 70-74. doi:10.1016/S0169-5347(02)00041-1

Thollesson, M., and Norenburg, J. L. (2003). Ribbon worm relationships: a phylogeny of the phylum Nemertea. Proceedings of the Royal Society of London. Series B, Biological Sciences 270, 407-415. doi:10.1098/ rspb.2002.2254
Whiting, M. F., Carpenter, J. M., Wheeler, Q. D., and Wheeler, W. C. (1997). The Strepsiptera problem: phylogeny of the holometabolous insect orders inferred from $18 \mathrm{~S}$ and $28 \mathrm{~S}$ ribosomal DNA sequences and morphology. Systematic Biology 46, 1-68.

Will, K., and Rubinoff, D. (2004). Myth of the molecule: DNA barcodes for species cannot replace morphology for identification and classification. Cladistics 20, 47-55. doi:10.1111/j.1096-0031.2003.00008.x

Wilson, G. D. F. (2008). Gondwanan groundwater: subterranean connections of Australian phreatoicidean isopods (Crustacea) to India and New Zealand. Invertebrate Systematics 22, 301-310. doi:10.1071/IS07030

Zhang, Z.-Q. (2011). Animal biodiversity: an introduction to higher-level classification and taxonomic richness. Zootaxa 3148, 7-12. 